BichU

DeptE

CenREST

- W

\#93-02

Center for Research on Economic and Social Theory

and

Department of Economics

Working Paper Series

A Survey of Theories

of the Family

Theodore C. Bergstrom

March, 1993

Number 93-02

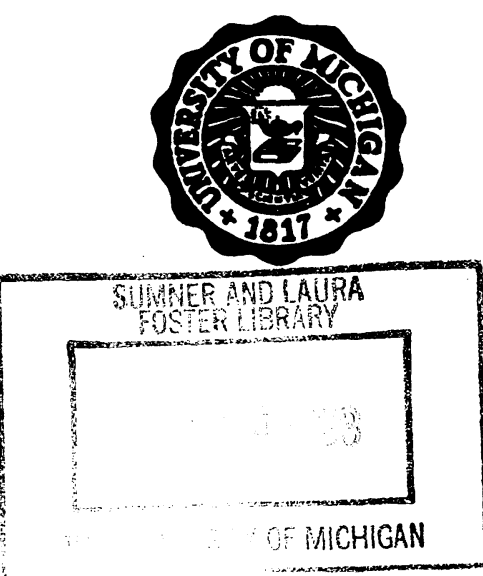

DEPARTMENT OF ECONOMICS

University of Michigan

Ann Arbor, Michigan 48109-1220 



\section{A Survey of Theories of the Family}

Ted Bergstrom

\section{A Survey of Theories of the Family}

by

\section{Ted Bergstrom}

University of Michigan

Current version: March 13, 1993
To a labor economist or an industrial organization economist, a family looks like " $\mathrm{a}$ little factory." To a bargaining theorist, a husband and wife are "two agents in a relation of bilateral monopoly." To an urban economist or a public choice theorist, a family looks like "a little city", or perhaps "a little club". To a welfare economist, a family is an association of benevolently interrelated individuals. Each of these analogies suggests useful ways in which the standard tools of neoclassical economics can aid in understanding the workings of a family.

The first section of this review draws on the analogies to a little factory and to a litthe city, in exploring the theory of household technology and the associated possibilities for distributiing utility among household members. The second section concerns decision theory within the household. This discussion draws on standard consumer decision theory, but also on the analogy of a family to a bilateral monopoly and to a little city in which certain public choices must be made. The third section of this paper deals with an equilbrium in which families are formed by persons voluntarily choosing mates. This theory is analogous to "Tiebout theory" in urban economics, where the objects of choice include not only the amount of public goods supplied in each city, but which individuals live in each place. An aspect of family life that has fewer parallels in the economics of market economies is intrafamilial love and altruism. The final section of this paper reviews a growing theoretical literature on love, altruism and the family.

\section{Section I. Household Technology and Utility Possibility Frontiers}

\section{I.1. Household Production Functions}

In his Treatise on the Family, Gary Becker (1981) emphasizes the importance of division of labor and gains from specialization. Drawing on his 1965 paper, "A Theory of the Allocation of Time", Becker endows households with household production functions which describe the possibilities for producing "household commodities", using market goods and the labor time of each individual in the household as inputs. The concept of production function, borrowed from the theory of the firm, has been a fruitful source of insight into the workings of families. Becker draws on this analogy to consider such issues as specialization within the household, comparative advantage, returns to scale, factor substitution, human capital and assortative mating.

Each individual in Becker's household can use time either for household labor or market labor. The family can purchase market goods and either consume them directly or use them as inputs into household production. Becker's examples of household commodities includes children, prestige and envy, health, and pleasures of the senses. He suggests that the number of household commodities is typically much smaller than the number of marketable goods. 
Robert Pollak and Michael Wachter (1975) develop the formal structure of Becker's household production model and show that if household commodities are produced with constant returns and no joint production, then "shadow prices" for these commodities are determined by goods prices and wage rates for market labor-independently of the quantities demanded. This means that the "production possibility set" is like an ordinary competitive budget set, in that it is the intersection of a half-space with the non-negative orthant, rather than a set with a curved boundary. ${ }^{1}$ Pollak and Wachter observe that with joint production or with nonconstant returns to scale, the shadow prices of commodities will depend on the quantities produced. In this case, the theory does not admit as simple a a separation of tastes and technology as when the production possibility frontier is linear. If such a separation is not possible, Pollak and Wachter suggest that there is little to be gained from adding unobservable produced commodities to the model. Instead they recommend studying the demand for market goods and for leisure directly as functions of goods prices and wages. They also suggest that tastes and technology can be confounded by treating such non-measurable aggregate variables as "child quality" as commodities and they recommend more narrowly-defined child-related commodities such as "scores on standardized tests" or "number of dental cavities."

As Pollak and Wachter point out, even with very general technologies, there will be well-defined demand functions for market goods and supply functions of labor which could in principle be determined from household utility. Trout Rader (1964) establishes general conditions under which "induced preferences" for trades inherit such properties as convexity, continuity and homogeneity from the production functions and the preferences for produced produced commodities. Richard Muth (1966) shows that even if the output of a household commodity is not directly observable, the assumption that this commodity is produced with constant returns to scale can have interesting testable implications. If for example, two or more market goods are used as inputs for this good and no other goods, then it must be that the income elasticities of demand for the two goods will be identical. A detailed discussion of the theory of household production and additional references can be found in Deaton and Muellbauer (1980).

\subsection{Household Public Goods}

A unit of private goods consumed by one person can not be consumed by another. But some goods, such as shared living space, household heating and lighting and shared automobile trips are jointly consumed and are best modelled as local public goods which enter simultaneously into the utility functions of all family members.

While Becker (1981) does not explicitly distinguish household public goods from private goods, his household technology model could certainly be used to describe production of household public goods as well as ordinary private goods. Murray Brown and Marilyn Manser (1980) and Marjorie McElroy and Mary Horney (1981) introduce household public goods as an integral part of their models of family behavior. They emphasize the benefits of

\footnotetext{
1 This result is essentially the generalized Samuelson nonsubstitution theorem for the "small-country
case" where factors can be purchased at constant prices. See Samuelson (1961) and Varian (1984)
}

shared public goods as a reason that marriage yields a utility surplus over living separately. Yoram Weiss and Robert Willis (1985), in their economic study of divorce and childsupport payments, treat the well-being of children as a local public good that enters the utility of both parents whether these parents are married or divorced. David Lam (1988) suggests that the presence of household public goods will favor positive assortative mating by income.

Household public goods are modelled as follows. Let $H$ be the set of household members. Each household member $i \in H$ has a utility function $U_{i}\left(x_{i}, y\right)$ where $x_{i}$ is the vector of private goods consumed by $i$ and where $y$ is the vector of household public goods. If there are $n$ private goods and $m$ public goods, the household is constrained to choose its aggregate consumption of private goods $x$ and its vector of private goods $y$ so that $(x, y) \subset S$, where $S \subset R^{m+n}$ is the household's aggregate feasibility set. The nature of this set is determined by the household budget and by household technology. In a household that consumes $(x, y)$, all consumers in the household consume the vector $y$ of public goods The aggregate vector $x$ of private goods between can be divided among its members in any way such that $\sum_{i \in H} x_{i}=x$.

\section{I.3. The Household Utility Possibility Frontier}

Many issues in the economics of households are illuminated by using the utility possibility frontier as an analytic tool. ${ }^{2}$ For a two-person household, the utility possibility frontie is constructed as follows. Where there are $n$ private goods and where the household public good vector has $m$ components, let the set $S \subset R^{m+n}$ denominate the combinations of aggregate private consumption vectors and public good vectors that the household can attain given its budget and its household production function. A feasible allocation for a household of $n$ persons is a vector $\left(x_{1}, \ldots, x_{n}, y\right)$ such that $\sum x_{i}=x$ where $(x, y) \in S$. Each feasible allocation corresponds to a feasible distribution of utilities among household members, where person $i$ gets utility $U_{i}\left(x_{i}, y\right)$. The northeast boundary of this set is the utility possibility frontier. Since by construction, there is no feasible way to make both persons better off than they are at a point on the frontier, all points on the utility possibility frontier correspond to Pareto optimal allocations of resources.

For any fixed vector $y$ of public goods, it is possible to construct a conditional utility possibility set $U P(y)$, such that $U P(y)$ corresponds to all of the distributions of utility that can be achieved when the public goods vector is $y$ and with a private goods allocation that is feasible for the household given that its public goods vector is $y$. The conditional utility possibility frontier corresponding to $y$ is the northeast boundary of $U P(y)$. In general, the conditional utility possibility frontiers corresponding to different public goods vectors may cross each other. The utility possibility frontier for the household will be the outer envelope of the conditional utility possibility frontiers corresponding to all feasible choices of $y$.

2 The utility possibility frontier seems to have been introduced to the economic literature by Paul Samuelson (1950), begins the section of his paper where this idea is introduced with the heading The
Crucially Important 'Utility Possibility Function. 


\section{I.4. Transferable Utility in the Household}

The term "transferable utility" seems to have originated in game theory, but the idea that it represents is familiar to all economists. In a world with one private good and no public goods, individual preferences can be represented by utility functions $u_{i}\left(x_{i}\right)=x_{i}$ where $x_{i}$ is $i$ 's consumption of the good. If there is a fixed total supply $X$ of the good and if it is possible to distribute the good in any way among individuals, then the utility possibility frontier is a simplex consisting of all utility distributions that sum $X$. If the total amount of the good available increases (decreases), the utility possibility frontier shifts uniformly outward (inward).

More generally, we say that there is transferable utility for a group of agents if utility functions can be found for each agent such that on the relevant portion of the group's utility possibility frontier the sum of utilities is constant and if the relevant utility possibility pontier moves inward or outwath in the group change. As we will see, the assumption of transferable utility has powerful and interesting implications in the the theory of the household-implications which do not hold in models without tranferable utility.

The domain of applicability of transferable utility is not as widely understood as it should be. Some economists and game theorists think there is more transferable utility than there really is and some think there is less. Those in the former camp believe that transferable utility obtains whenever preferences are continuous and there exists a divisible and fully exchangeable good that is desired by all consumers. Those in the latter camp think that transferable utility applies only in the very special case of "quasilinear utility", where utility is linear in the quantity of some commodity. As we will see, neither of these views is correct.

\section{Transferable Utility with Private Market Goods}

In general, for a closed economy with two or more goods there will not be transferable utility. In a two-person pure exchange economy where preferences are continuous and monotonic in the two goods, the utility possibility frontier is smooth and "downwardsloping." For a given aggregate endowment of resources, it would be possible to make a monotone transformation of each person's utility in such a way that in the transformed utilities the utility possibility frontier is a simplex. ${ }^{3}$ So why isn't there transferable utility? The problem is that in general, a change in the aggregate endowment of either good would Typically the utility possibility frontier corresponding to the utility function $V(x)$ which

\footnotetext{
3 For an arbitrary choice of utility functions, the utility possibility frontier would be defined by an equation $U_{2}=F\left(U_{1}\right)$, where $F$ is a strictly decreasing function. Define the new utility functions $V_{1}(x)=$ $g_{1}\left(U_{1}(x)\right)=U_{1}(x) /\left(U_{1}(x)+F\left(U_{1}(x)\right)\right)$ and $V_{2}(x)=g_{2}\left(U_{2}(x)\right)=U_{2}(x) /\left(U_{2}(x)+F^{-1}\left(U_{1}(x)\right)\right.$ Since $F$ is strictly monotone, the functions $g_{1}$ and $g_{2}$ are well-defined and strictly monotone increasing. Every $\left(g_{1}\left(U_{1}\right), g_{2}\left(U_{2}\right)\right)$ such that $V_{1}+V_{2}=1$. Thus the utility possibility frontier with the utility representations $V_{1}(x)$ and $V_{2}(x)$ lies on a simplex.
}

we defined to "straighten out" the utility possibility frontier with one endowment would yield a utility possibility frontier that does not lie on a simplex, but is "curved".

It is well-known that there will be transferable utility if all utility functions take the quasilinear form $U_{i}\left(x_{i}\right)=x_{i 1}+f_{i}\left(x_{i 2}, \ldots, x_{i n}\right)$, where $x_{i j}$ is the amount of commodity $j$ consumed by person $i$ and where $f_{i}$ is a strictly concave function. With quasilinear utility, it must be that at every interior Pareto optimum, all consumers have the same marginal utilities for goods 2 through $n$. Since the functions $f_{i}$ are strictly concave, this marginal utilities for goods 2 through $n$. Since the functions $f_{i}$ are strictly concave, this
determines a unique allocation of goods 2 through $n$, namely the allocation that maximizes $\sum_{i} f_{i}\left(x i 2, \ldots, x_{i n}\right)$ subject to $\sum_{i} x_{i j}=x_{j}$ for $j=2, \ldots, n$. Different points on the utility possibility frontier are achieved only by reallocation of good 1 . Since utility is linear in $x_{i 1}$ for all $i$, the utility possibility frontier is a simplex.

If preferences are quasilinear, then for any consumer who chooses a positive amount of good 1 , the income elasticity of demand for each of the other goods is zero and the marginal propensity to consume good 1 out of income is 1 . In most applications, the assumption that there are no income effects on demand is so unrealistic that if the existence of transferable utility replied quasilinearity, there would be little excuse for assuming transferable utility As it happens, transferable utility applies in a considerably larger class of cases.

Bergstrom and Hal Varian (1985) showed that in a pure exchange economy with private goods there will be transferable utility if and only if preferences of all individuals can be represented by indirect utility of the Gorman polar form. Indirect utility is of the Gorman polar form if it can be expressed in the form $v_{i}(p, m)=\alpha(p) m+\beta_{i}(p)$ for each individual $i$. This is the case if and only if income-consumption paths for all consumers are parallel straight lines, the slopes and intercepts of which may depend on prices.(See Gorman (1953)). Preferences in the Gorman class include quasilinear utility, but they also include identical homothetic preferences and more generally, preferences which, like the Stone-Geary utility function, are represented by utility functions of the form $U\left(x-e_{i}\right)$ where $U$ is a homgeneous function and $e_{i}$ is some vector which "displaces the origin" and which may be different for different people. Thus it is possible to have transferable utility and to have demand for all goods being positively reponsive to income.

Except for unusual cases like that of poor Robinson Crusoe and Friday, households are not closed economies. Most households are small relative to the economies in which they live and are price takers for market goods. If family members are selfish and if the only goods they consume are marketable private goods then the "Hicks composite commodity goods" cllow "wodity". Wealth favorite bundles at market prices. There will be transferable utility where each individual's utility is represented by the amount of wealth which he or she is given to spend. This model can even accommodate household labor supply if each household member is a price-taker in the labor market. This can be done with the usual trick of treating each person $i$ 's leisure as a commodity which is marketable at some price $w_{i}$. Total household income includes the value of each person's potential amount of leisure evaluated at that person's wage. Individuals are allocated shares of total household income and are able to "buy" their leisure at the market wage. 
Where total household wealth is $W$ and the vector of market prices is $p$, the set of allocations possible for the household is $\left\{\left(x_{1}, \ldots, x_{n}\right) \mid p \sum_{i} x_{i} \leq W\right\}$. Consider any allocation $\left(\bar{x}_{1}, \ldots, \bar{x}_{n}\right)$ that is Pareto optimal for the household. It must be that for each $i$, $\bar{x}_{i}$ maximizes $U_{i}\left(x_{i}\right)$ subject to the budget constraint $p x_{i} \leq p \bar{x}_{i}{ }^{4}$ Therefore each Pareto optimal allocation corresponds to an allocation achievable by choosing a household income distribution $\left(W_{1}, \ldots, W_{n}\right)$ such that $\sum_{i} W_{i}=W$ and allowing $i$ to choose $x_{i}$ to maximize $U_{i}\left(x_{i}\right)$ subject to $p x_{i} \leq W_{i}$. If prices are given parametrically and household members selfish, individual $i$ will always prefer to have a higher $W_{i}$ rather than a lower one, so that $W_{i}$ will serve as a utility function for each individual. The household utility possibility frontier is the simplex $\left\{\left(U_{1}, \ldots, U_{n}\right) \mid \sum U_{i}=W\right\}$.

\section{Transferable Utility with Household Production}

If the household produces and consumes non-marketable commodities, as in the Becker model of household production, there still can be transferable utility. If household production occurs with single-output production functions characterized by constant returns to scale and if there no more than one non-marketed commodity is used as an input, then the generalized Samuelson nonsubstitution theorem Samuelson (1961) implies that the production possibility frontier for the produced commodities is a simplex. This means as Pollak and Wachter (1976) and Varian (1984) point out, that there exist "shadow prices". for the produced commodities which are determined by technology and the price of marketable goods, independently of the quantities demanded. With this setup, just as in the case where all consumption goods are marketable, there will be transferable utility without special assumptions about the utility function. If, on the other hand, there are nonconstant returns to scale in household production or if there is more than one nonmarketable (and nonproduced) input, then there will typically not be transferable utility.

Transferable Utility with Household Public Goods

Transferable utility does not so easily survive the introduction of household public goods. Consider a household with two persons, one private good and one household public good. Preferences of persons 1 and 2 are representable by the utiity functions $U_{1}\left(x_{1}, y\right)=x_{1} y^{1 / 2}$ and $U_{1}\left(x_{2}, y\right)=x_{2} y^{3 / 2}$ respectively, where $x_{i}$ is $i$ 's consumption of the private good and $y$ is the amount of public good in the household. Total family wealth is $W$ and private goods as well as public goods can be purchased in the market at at price of 1 .

If the amount of public goods is fixed at an arbitrary level $y$, one can draw the conditional utility possibility frontier consisting of utility distributions achievable under alternative redistributions of private goods. The slope of this conditional utility possibility frontier is

$$
-\frac{\partial U_{1}\left(x_{1}, y\right)}{\partial x_{1}} / \frac{\partial U_{2}\left(x_{2}, y\right)}{\partial x_{2}}=-y^{1 / 2} / y^{3 / 2}=-y .
$$

4 If person $i$ preferred a bundle $x_{i}^{\prime}$ that cost no more than $\bar{x}_{i}$, then $\left(\bar{x}_{1}, \ldots, x_{i}^{\prime}, \ldots \bar{x}_{n}\right)$ would be Pareto superior $\left(\bar{x}_{1}, \ldots, \bar{x}_{n}\right)$ and would satisfy the household budget constraint. Notice that because of the linear
of the household budget constraint, this result does not require the assumption of convex preferences.
The full utility possibility frontier is the outer envelope of these conditional utility possibility frontiers. Each point on the utility possibility frontier corresponds to some Pareto efficient allocation. In this example, a necessary and sufficient condition for an interior Pareto efficient allocation is that the sum of marginal rates of substitution between public and private goods is 1 and that the allocation satisfies the household budget constraint $x_{1}+x_{2}+y=W$. The sum of marginal rates of substitution equals 1 when $y=x_{1} / 2+3 x_{2} / 2$ It follows from these two equations that $y=W / 2+\left(x_{2}-x_{1}\right) / 4$ at any Pareto optimal al location $\left(x_{1}, x_{2}, y\right)$. Therefore different points on the utility possibility frontier correspond to different quantities of $y$. Since the slope of the utility possibility frontier has been shown to be $-y$, the utility possibility frontier is not be a simplex.

A simple example of a household with transferable utility and two goods is the following Consider a two-person household with one private good and one household public good. Suppose that the household has a fixed amount of wealth $W$ to spend, and that it can buy private goods at a price of 1 or public goods at a price of $p$. Then the set of feasible aggregate consumptions is $S=\{(x, y) \geq 0 \mid x+p y \leq W\}$. Suppose that each consumer's utility function takes the special (quasilinear) form $\bar{U}_{i}\left(x_{i}, y\right)=x_{i}+f_{i}(y)$, where $f_{i}^{\prime}(y)>0$ and $f_{i}^{\prime \prime}(y)<0$. The first-order necessary condition for an interior Pareto Optimum is that the sum of marginal rates of substitution between public and private goods is $p$. (Samuelson (1954)). ${ }^{5}$ Since utility is linear in private goods, this condition is simply $f_{1}^{\prime}\left(y^{*}\right)+f_{2}^{\prime}\left(y^{*}\right)=p$, which has a unique solution for $y^{*}$ since $f_{i}^{\prime \prime}(y)<0$ for all $y$. Any allocation $\left(x_{1}, x_{2}, y^{*}\right) \geq 0$ such that $x_{1}+x_{2}+p y^{*}=W$ will be Pareto optimal.

Bergstrom and Cornes (1981), (1983) find general conditions under which economies with public goods have transferable utility. Their results as applied to two-person households are that a (essentially) necessary and sufficient condition for transferable utility is that preferences of each household member are representable by a utility function of the form $U_{i}\left(x_{i}, y\right)=f(y) x_{i}+g_{i}(y)$, where $x_{i}$ is the amount of the private good received by person $i$ and $y$ is the vector of public goods in the household. This functional form includes the special case of quasilinear utility where $U_{i}\left(x_{i}, y\right)=x_{i}+f_{i}(y)$. It also includes the case of identical Cobb-Douglas utility functions as well as cases where preferences are not identical and household demand for public goods is responsive to income. Households in which preferences satisfy the Bergstrom-Cornes condition have the following special properties:

- All points on the utility possibility frontier that correspond to interior Pareto optima are achieved with the same amount of public goods, $y=y^{*}$.

- The conditional utility possibility frontiers $U P F(y)$ and $U P F\left(y^{\prime}\right)$, corresponding to any two different quantities of public goods $y$ and $y^{\prime}$ will not cross each other. One or the other of these two frontiers lies strictly to the northeast of the other.

- The unique amount of public goods that corresponds to interior Pareto optimal allocations can be found by choosing $\left(x^{*}, y^{*}\right)$ to maximize $U_{1}\left(x_{1}, y\right)+U_{2}\left(x_{2}, y\right)=x+f_{1}(y)+$

5 An interior Pareto optimum is one where each consumer has positive consumption of private goods no private goods and where the Samuelson condition is not satisfied. This is explained by Bergstrom and no private goods and where the Samuelson condition is not satisfied.
Cornes (1983) and in more detail by Campbell and Truchon (1988). 
$f_{2}(y)$ subject to the joint budget constraint $x+p y=W$.

- All points on the utility possibility frontier corresponding to interior Pareto optima are reached by selecting the amount $y^{*}$ of public goods and distributing the quantity $x^{*}=W-p y^{*}$ of private goods among household members.

- The utility possibility frontier is a straight line segment with slope -1 extending from the point $\left(U_{1}, U_{2}\right)=\left(f_{1}\left(y^{*}\right), W-p y^{*}+f_{2}\left(y^{*}\right)\right)$ to the point $\left(U_{1}, U_{2}\right)=\left(W-p y^{*}+\right.$ $\left.f_{1}\left(y^{*}\right), f_{2}\left(y^{*}\right),\right)$.

\section{A Generic Model of a Household with Transferable Utility}

In general, it would be possible for any male and female to determine the utility possibility frontier that would apply to them if they should choose to marry. The pure theory of public goods is well-suited to analyzing this frontier. The applicability of the public goods model to jointly consumed household commodities such as heat, light, or a well-tended garden is apparent. But many joint household decisions that do not directly involve consumption also fall into this framework. For example, if two people marry each other, they must marry on the same date. They must also make a joint decision about where to live, how many children to have, how to educate the children and what size of estate to leave them.

Let us represent the list of joint decisions made by a couple by the vector $Y$. Suppose that if male $m_{i}$ marries female $f_{j}$ and they choose the vector $Y$ of household public choices and have private consumptions $X_{m_{i}}$ and $X_{f_{j}}$, then their utilities will be respectively:

$$
U_{m_{i}}=A(Y) X_{i}+B_{m_{i}}(Y, j) \text { and } U_{f_{j}}=A(Y) X_{j}+B_{f_{j}}(Y, i) .
$$

These utility functions indicate three things a person must consider when he or she contemplates a potential marriage. These are: (a) the effect of the vector $Y$ of public choices that would be made in this marriage, (b) the amount of private goods that he or she would get to consume in that marriage, and (c) his or her feelings about the desirability of the other person as a marriage partner. (This last effect is registered by the fact that the functions $B_{m_{i}}(Y, j)$ and $B_{f_{j}}(Y)$ depend not only on $Y$ but also on the name of one's partner.)

The consumption options available to a potential pair of spouses depends on their joint economic productivity. For each male and female $m_{i}$ and $f_{j}$, let the set of affordable combinations of private consumptions and public choices be all vectors $\left(X_{m_{i}}, X_{f_{j}}, Y\right)$ which satisfy the equation:

$$
X_{m i}+X_{f j}<F_{i j}(Y)
$$

This technical formulation is very general. The only real restriction involved here is that it is technically possible to distribute the private good in any way between the two individuals.
Then for any couple, $m_{i}$ and $f_{j}$, the part of the utility possibility frontier corresponding to allocations where both persons get positive consumptions of private goods is described by the linear equation

$$
U_{m_{i}}+U_{f j}=A_{i j}
$$

where $A_{i j}$ is the maximum of

$$
A(Y) X+B_{m_{i}}(Y, j)+B_{f j}(Y, j)
$$

subject to the constraint $X \leq F_{i j}(Y)$ where $X=X_{m_{i}}+X_{f j}$

In this case, the problem of finding a Pareto efficient allocations within a potential marriage reduces to a constrained maximization problem in the aggregate quantities $X$ and $Y$. The corresponding utility possibility frontier is a simplex consisting of utilities that add to $A_{i j}$.

\section{Section II. Decision-Making in the Family}

After proving that in general there do not exist "social indifference curves" that rationalize aggregate demand, Samuelson (1956) worries that

"But haven't I in a sense proved too much? Who after all is the consumer in the theory of consumer's (not consumers') behavior? Is he a bachelor? A spinster? Or is he a "spending unit" as defined by statistical pollsters and modern economists, the fundamental unit on the demand side is clearly the "family" and this consists of a single individual in but a fraction of cases."

Economists are not the only social scientists to be concerned about whether the family should be treated as a decision-making agent. The issue is nicely posed by the sociologist, James Coleman (1990, page 580).

"The family has always been an entity within which multiple activities are carried out: economic production, joint consumption, procreation, socialization of children, and leisure pursuits. Generally it cannot be regarded as a purposive actor ... for it cannot usually be described as having a purpose for which it acts. It is, like society as a whole but on a smaller scale, a system of action composed of purposive actors in relation. Yet in some capacities the family may be usefully regarded as a purposive actor for it is an entity in terms of whose perceived interests natural persons act, for example some persons say they are acting to "uphold the honor of the family." And in some cases a family does act as a unit, to attain ends that can be described as purposes or goals of the family.

It may be useful to clarify when and for what purposes a system of action should be called an actor. For example, in a swarm of insects hovering in the summer air, each insect is darting this way and that, apparently either randomly or in pursuit of its own ends. But the swarm as a whole will move this way or that, hover expand or contract, and then fyy off no less coherently than if it were a single organism. ... Thus just as a swarm of insects may be 


\section{II.1. Unitary Theories of Family Decision Making}

At least until recently, empirical studies of household demand have usually assumed that a family will act as if it is maximizing a "family utility function". ${ }^{6}$ That they should have done so is understandable since most of the available cross-sectional data on household consumption consists of household agrregates which do not distinguish either the incomes raised about this approach were amplified by the work of Mansur and Brown (1980) and McElroy and Horney (1981), who showed if the allocation of resources within the family is determined by Nash bargaining, then household aggregate demand functions can not in general be rationalized by maximization of a family utility function.

Theories in which household demand can be rationalized by a family utility function have at various times been called "single-agent", "common preference ", "consensus", "altruistic", or "benevolent dictator" theories. ${ }^{7}$ We follow the suggestion of Chiappori, Haddad, Hoddinott, and Kanbur (1992) in designating this class of models as unitary models. This name is sufficiently broad to encompass the several different models of family structure that predict that a family's aggregate behavior is "as if" it is maximizing a family utility function.

For some models of preferences and decision-making, aggregate behavior of the family is determined by prices and aggregate income independently of income distribution, even though the distribution of consumption within the family depends on income distribution. Other models of the family predict that changes in the distribution of income within the family will not change any family member's income, so long as total family income is unchanged.

Let us explore some of these ideas in the context of a unitary model of a household in which both public and private goods are consumed and where both types of goods are purchased in competitive markets. Let $H$ be the set of individuals in a household. Let $x_{i}$ be the vector of private goods consumed by household member $i$ and let $y$ be the vector of household public goods available in the household. The household's aggregate consumption of private goods is given by $x=\sum_{i \in H} x_{i}$. Let $p_{x}$ be the vector of market prices for private goods and let $p_{y}$ be the vector of market prices for public goods. The household budget set is $B\left(p_{x}, p_{y}, W\right)=\left\{(x, y) \geq 0 \mid p_{x} x+p_{y} y \leq W\right\}$. The household utility function

${ }^{6}$ Good surveys of this work can be found in Deaton and Muellbauer (1980) and Browning (1992).

7 Some economists refer to single-agent theories of the family as the "neoclassical theory of the family". ( theories of the family fall squarely within the neoclassical tradition. A distinctive features of neoclassical microeconomics is "methodological individualism". When faced with fundamental questions about group behavior, neoclassical economists typically take a reductionist approach and seek to explain group behavior $n$ not as a choice of a single rational agent, but rather as the result of the interplay of actions by group mes-
bers with distinct objectives. It is true that neoclassical economists such as (Gorman (1953), Samuelson (1956), and Becker(1974) have explored special assumptions on preferences under which families act as maximizing agents. It is also true that econometricians have often tried to simplify the task of applying neoclassical theory to household data by assuming that they act like a single agent. But this does no mean that the natural course of neoclassical economics is to assume that families act like single agents. is $U(x, y)$ and the household chooses an aggregate consumption $(x, y)$ to maximize $U(x, y)$ on $B\left(p_{x}, p_{y}, W\right)$. When household aggregate demand satisfies this condition, household demand is said to be "integrable." According to standard results in consumer demand theory, household demand will be integrable if and only if it satisfies the weak and strong axioms of revealed preference. Sufficiently differentiable demand functions will be integrable if and only if they satisfy the "Slutsky symmetry conditions". (See, for example, Deaton and Muellbauer (1980).)

In a household with private goods only and where individuals have identical and homothetic preferences, aggregate consumption by the household is determined by prices and aggregate income independently of income distribution within the household. More generally, so long as there are no household public goods, the aggregation results of W.M Gorman (1953) and Samuelson (1956) can be applied. Gorman showed that there exist "community preference fields" and Samuelson equivalently showed that there exist "socia indifference curves" that rationalize group behavior if and only if individual preferences satisfy certain restrictive properties. Household demand can be rationalized as maximizing a single preference relation subject to a household budget constraint if and only if indirect utility functions of all household members are of the "Gorman polar form", $v_{i}\left(p, m_{i}\right)=\alpha(p) m_{i}+\beta_{i}(p)$. This is the case if and only if income consumption paths for all consumers are "parallel straight lines". If income consumption paths are not of this form then total household consumption depends on the distribution of income as well as total family income. The reason is easy to see. If two family members have different marginal propensities to consume a good out of additional income, then redistributing a dollar from one person to the other will change aggregate demand for that good although neither prices nor family income have changed. But if they have the same marginal propensities, then the increase in consumption of any good by the gainer will be just offset by the reduction in consumption of the loser. To an observer who sees only aggregate consumption, there would be no change.

While the Gorman polar form is restrictive, it provides an interesting class of exam ples of economies for which econometricians who can observe only household aggregates are justified in using a "family utility function". Where there several private goods, but no public goods, quasilinear utility functions of the form $x_{1}+f\left(x_{2}, \ldots, x_{n}\right)$ fall into the Gorman class, as do Stone-Geary utility functions and more generally, any family of "translated homothetic utility functions" such that for each $i, U_{i}\left(x_{i}\right)=U\left(x_{i}-e_{i}\right)$, where $U$ is a homogeneous function.

The Gorman results concern families with private goods and no public goods. The results of Bergstrom and Cornes, (1981), (1983) on transferable utility with public goods (discussed above) delineate the rather large class of special utility functions for which the unitary model applies when there are public as well as private goods.

Under the Gorman and Bergstrom-Cornes conditions, the unitary model of the household applies because aggregate demand is independent of the way income is distributed within the household. Samuelson (1956) and Varian (1984) point out that if income distribution within the family is itself the result of an optimizing choice, then even for very general individual preferences, aggregate household demand will behave as if it is the de- 
mand of a single maximizer. Consider a model in which each household member has a quasi-concave utility functions over private goods and household public goods of the form $U_{i}(x, y)$ and that income distribution within the family is decided by a benevolent dictator who has a utility function of the form $W\left(U_{1}\left(x_{1}, y\right), \ldots, U_{n}\left(x_{n}, y\right)\right)$. The dictator could solve for the allocation $\left(x_{1}^{*}, \ldots, x_{n}^{*}, y^{*}\right)$ which maximizes $W\left(U_{1}\left(x_{1}, y\right), \ldots, U_{n}\left(x_{n}, y\right)\right)$ subject to $p_{x} \sum_{i \in H} x_{i}+p_{y} y \leq W$ and implement this outcome by providing the family with $v^{*}$ and giving fally me define the function $V(x, y)$ to be the maximum of $W\left(U_{1}\left(x_{1}, y\right), \ldots, U_{n}\left(x_{n}, y\right)\right)$ subject to $\sum x_{i}=x$, then it will be the case that aggregate demand in this family is always chosen so as to maximize $V(x, y)$ subject to the family budget constraint.

Samuelson suggests that even if a family is not a dictatorship, it might be that

"“"preferences of the different members are interrelated by what might be called a 'consensus' or 'social welfare function' which takes into account the deservingness or ethical worths of the consumption levels of each of the members. The family acts as if it were maximizing their joint welfare function."

The joint welfare function that Samuelson has in mind is a function of the form $W\left(U_{1}\left(x_{1}, y\right), \ldots, U_{n}\left(x_{n}, y\right)\right)$ where $W$ is an increasing function of each family members's utility. A utility function of this kind is known as a Bergson-Samuelson social welfare function. ${ }^{\mathrm{B}}$

If a family chooses allocations to maximize a Bergson-Samuelson social welfare function subject to a family budget constraint, then the family's aggregate consumption is rationalized by some utility function $V(x, y)$ where $V(x, y)$ is the maximum of

$$
W\left(U_{1}\left(x_{1}, y\right), \ldots, U_{n}\left(x_{n}, y\right)\right)
$$

subject to the constraint that $\sum_{i}^{N} x_{i}=x$. Therefore it is impossible using family aggregate data to distinguish the consumption behavior of a family that maximizes from the behavio of a single rational consumer. If $W$ is a concave function of the $x_{i}$ 's then it will also be true that the consumption of each family member is uniquely determined by aggregate family income.

E. Eisenberg (1961) discovered that if each family member always gets a constant fraction of income and if all family members have homothetic, but not necessarily identical preferences then family demand can be rationalized as the choice of a single individual This idea was clarified and generalized by John Chipman (1974), Wayne Shafer (1977) and Perry Shapiro (1977). The difference between the Eisenberg theorem and the Gorman and Perry Shapiro (1977). The difference between the Eisenberg theorem and the Gorman bution have no effect on aggregate demand. Eisenberg demands only that a family where income is always distributed according to predetermined fractions in order to behave like a single consumer. B A social welfare function of this type was introduced to economics by Abram Bergson (1938) and
further developed by Samuelson (1947).

\section{The Rotten Kid Theorem}

Gary Becker's "Rotten Kid Theorem", $(1974,1981)$ establishes a different set of circumstances under which households act as if there were governed by a single, utility-maximizing decision maker. In Becker's model, it is also true that (over a certain range of incomes) the consumption of individual household members is not changed by income redistribution within the family. In Becker's model, there is one consumption good and no public goods. There is a single, benevolent parent and $n$ selfish "kids", who care only about their own consumptions. The parent's utility is given by $U\left(x_{0}, \ldots, x_{n}\right)$ where $x_{0}$ is the parent's consumption and $x_{i}$ is the $i$ th kid's consumption. Each kid $i$ has an income, $m_{i}$. The parent's income $m_{0}$ is much larger than that of the kids and he chooses to make "gifts" to each of them sim consumption in the family after gifts have been made will be the distribution $x_{0}^{*}, \ldots, x_{n}^{*}$ that maximizes the parent's utility, $U\left(x_{0}, \ldots, x_{n}\right)$ subject to $\sum_{i=0}^{n} x_{i}=\sum_{i=0}^{n} m_{i}$. If each kid's consumption enters the parent's utility function as a "normal good", then each kid's outcome will be an increasing function of total family income, $\sum_{i=0}^{n} m_{i}$. If each person in the family chooses an action $a_{i}$ that influences income of other family members but does not influence utility directly, then it follows that all persons in the family seek to maximize total family income. The problem of choosing the actions $a_{i}$ is therefore of the type that Marshak and Radner (1972) describe as a problem in "team theory". 9

Assar Lindbeck and Jörgen Weibull (1988) and Neil Bruce and Michael Waldman (1990) show that parental altruism can lead to inefficiency in a multi-period model. A similar source of inefficiency in the context of government welfare programs was named the "Samaritan's Dilemma" by James Buchanan (1975)..$^{10}$ In the Bruce-Waldman model if parents make transfers to their children in the second period, then children will do too little saving. But if parents confine their transfers to the first period, then children will have no incentive to maximize joint family income in the second period. Lindbeck and Weibull extend the analysis to cases where there is mutual benevolence between "parent" and "child". They also point out that an important instance of this problem is to the case of children supporting indigent parents. Parents will have too little incentive to save for their old age if they believe that the amount of support they will receive from their children will be larger, the less resources their aged parents have.

Bergstrom (1989), and David Johnson (1990) show when there is more than one good or when the income-influencing actions $a_{i}$ have a direct effect on utility, the Rotten Kid Theorem does not apply. These authors show that the Rotten Kid Theorem extends to environments with multiple commodities and actions which influence utility directly 9 It should be recognized that Becker's results are not a trivial consequence of the household head being
a "dictator." As Becker (1974) remarks, although the head is not able to choose consumption distributions, he is not able to dictate the actions $a_{i}$ that determine individual incomes. Nevertheless, because of the head's distributional actions, all individuals in the family will agree on the same objective function to pursue in their choices of the $a_{i}$ 's, namely maximization of total family income.

10 The biblical New Testament parable of the "Prodigal Son", Luke XV 11-32, seems more appropriate to this problem than the parable of the "Good Samaritan". 
if there is transferable utility. They argue further that transferable utility is essentially necessary as well as sufficient for the Rotten Kid theorem to apply. Although the assumption of transferable utility is restrictive, there remains a fairly broad and interesting class of households that satisfy transferable utility and for which the Rotten Kid Theorem, appropriately interpreted, is of interest.

\section{II.2. The Family with Pluralistic Decision-Making}

Just as there is an equilibrium theory of a general competitive economy with many consumers, so there is a useful theory of the family even if aggregate consumption can not be rationalized as the choice of a single consumer.

\section{Proportional Sharing Rules}

One of the simplest possible models of household consumption assumes that household income is always divided in prespecified proportions between household members and where there are no public goods. Each household member chooses his or her own consumption bundle to maximize utility subject to the resultiing budget constraint. Samuelson (1956) calls this division rule an example of a shibboleth and points out that in general, dividing income in proportions that do not change when prices change would be inconsistent with maximizing the utility of a benevolent parent or with maximizing a well-defined socia welfare function. 11

\section{Cooperative Nash Bargaining Solutions}

Manser and Brown (1980) and McElroy and Horney (1981) applied the Nash cooperative bargaining model to marriages. These authors model marriage as a static bilateral monopoly in which a man and a woman can either marry or remain single. If they marry they can both be made better off than if they remain single. The division of the potentia gains from marriage is determined by the symmetric Nash bargaining model, where the threat point is that they dissolve the marriage. If they are married, each party to the marriage has a utility function of the form $U_{i}\left(x_{i}, y\right)$ where $x_{i}$ is $i$ 's vector of consumption of private goods (including leisure) and $y$ is the vector of household public goods that they share. There is a vector of prices $p_{x}$ for private goods and $p_{y}$ for public goods. The set of possible allocations of goods within the marriage consists of all vectors $\left(x_{1}, x_{2}, y\right)$ such that $p_{x} x_{1}+p_{x} x_{2}+p_{y} y=W_{1}+W_{2}$, where $W_{i}$ is the "full income" of household member

\footnotetext{
11 A nice diagram that illustrates why the demands that result from the proportional division rule are not consistent with behavior of a single decision-maker can be found in Hicks. (1956), page

12 As Samuelson acknowledges, demands resulting from proportional income division would be rationalizable as the demand of a single consumer if preferences were identical and homothetic. Eisenberg (1961)
} as everyone's preferences are homothetic. $i^{13}$ Given this information, it is possible to construct the utility possibility set within this marriage. The utility that each person can achieve if the marriage is dissolved depends on prices and on his or her full income. Where $V_{i}$ is $i$ 's utility if the marriage is dissolved, the symmetric Nash bargaining solution is the utility distribution $\left(U_{1}^{*}, U_{2}^{*}\right)$ that maximizes $\left(U_{1}-V_{1}\right)\left(U_{2}-V_{2}\right)$ on the utility possibility set. ${ }^{14}$

If the threat points $V_{1}$ and $V_{2}$ were independent of prices and individual wealths, then in a household governed by Nash bargaining, aggregate demand could be rationalized by the family utility function $W\left(x_{1}, x_{2}, y\right)=\left(U_{1}\left(x_{1}, y\right)-V_{1}\right)\left(U_{2}\left(x_{2}, y\right)-V_{2}\right)$. Aggregate demand would obey the Slutsky conditions and the revealed preference axioms. But in the model proposed by Mansur and Brown and by McElroy and Horney, the threat points $V_{i}$ represent the utility levels that each person could achieve if he or she were not married. These threat points generally will depend both on prices and on individual incomes. Since the parameters $V_{i}$ depend on prices and incomes, the family aggregate utility function $\tilde{U}$, unlike the utility function of ordinary neoclassical consumers, depends on prices and the distribution of incomes as well as on consumption. McElroy and Horney work out the "generalized Slutsky matrix" that corresponds to this situation and show that it will not in general be symmetric.

Robert Pollak and Shelly Lundberg propose an alternative Nash bargaining model. They suggest that for many marriages, the relevant threat point for the Nash bargaining solution should be not divorce, but an "uncooperative marriage" in which spouses would revert a "division of labor based on socially recognized and sanctioned gender roles." Their model makes the following prediction that differs strikingly from the divorce-threat models and from the Becker, Rotten Kid model: If government child-allowances are paid to mothers rather than to fathers in two-parent households, the threat point envisioned by Pollak and Lundberg is likely to shift in the mothers' favor. Accordingly, the outcomes of cooperative bargaining within households are likely to be more favorable to women. By contrast in the divorce-threat models, if in the event of divorce the mother gets the children and the child allowance, then the outcome of household bargaining will not be affected by whether the child allowance is paid to mothers or fathers. Similarly in the Becker model, the well-being of each household member is determined by total family income, independently of intrafamily income distribution.

\section{Empirical tests of the unitary model of family decision-making}

McElroy (1990) observes that empirical tests of the unitary model of family decision making are possible if one has data on aggregate household consumption and on other variables

13 When we treat leisure as a commodity, full income is the value at market prices of a person's initial endowment of nonhuman wealth plus the value of the total amount of labor the person could supply to the market.

14 This expression is sometimes known as the Nash product. John Nash (1950) proposed a set of axioms for resolution of static two-person bargaining games such that the only outcomes that satisfy the axioms maximize the Nash product on the utility possibility set. 
which may affect an individual's threat point, such as individual wage rates and on unearned incomes specific to each household member. If, holding prices and incomes constant, the distribution of wealth within the household has significant effects on demand, then one would reject the unitary hypothesis. Stronger tests will be possible if one is also able to separately observe the consumption of the husband and the wife. For many commodities, this is very difficult. However recent studies have been able to determine separately the consumption of leisure by each household member and the consumption mens' and womens' clothing within each household.

Schultz (1990) finds that in Thailand, an increase in a woman's unearned income from outside the household will have a larger negative effect on the probability that she joins the labor force than dees an equal increase in her husband's unearned outside income. Marting Bourguignon, Pierre-André Chiappori, and Valérie Lechene (1992) find that in Canada the shares of the family budget devoted to mens' clothing and to womens' clothing are positively related respectively to the shares of family income earned respectively by men and women. Using data from a household survey from the Cote d'Ivoire, John Hoddinott and Lawrence Haddad (1991) find that "increases in the proportion of cash income accruing to women significantly raises the budget shares of food and lowers those of alcohol and cigarettes.

The results found by Schultz, Browning et al, and Hoddinott and Haddad would not be observed in a unitary model of household demand. Schultz is able to peek inside the family black box and observe separate consumptions of leisure by husbands and by wives. Hoddicott and Haddad do not directly observe which household members consume the food or the alcohol and cigarettes, nor do Browning and his coworkers know who wears the trousers in Canadian families. The finding that an increase in the wife's share of family income tends to increase consumption of food and women's clothes and an increase in the husband's share tends to increase consumption of cigarettes, alcohol, and men's clothes is, however, indirect evidence that men in Cote d'Ivoire consume more cigarettes and alcohol than women, and that people in Canada tend to wear gender-appropriate clothing.

Duncan Thomas (1990) finds evidence that in Brazilian families, unearned income of the mother has a much stronger positive effect on fertility and on measures of child health such as caloric intake, weight, height, and survival probability than unearned income of the father. For fertility and measures of caloric intake, the effect of mothers' income is about 8 times as large as that on fathers' income. For survival probability, the effect of mothers' income is nearly 20 times as large. Hoddinott and Haddad find that childrens' height for age is positively related to the share of family wealth controlled by their mothers. Schultz (1990) finds that an increase in a woman's unearned income tends to increase her fertility while an increase in her husband's unearned income does not. Unlike the private goods studied by Schultz and by Browning et al, child health and fertility are household public goods jointly "consumed" by both the husband and wife. In order to explain the effect of income redistribution in the family on the family demand for public goods, we need a different theory than the private goods theory. Thomas's result would not follow simply from the observation that women are more interested in the welfare of their children than their husbands are. If, for example, utilities were of the form $U_{i}\left(x_{i}, y\right)=A(y) x_{i}+B_{i}(y)$ where $y$ is the child's welfare and $x_{i}$ is $i$ 's private consumption, the wife could have a higher marginal rate of substitution between child's welfare and own consumption than the husband, but the Pareto efficient expenditure on child care would be invariant to income distribution within the family. For Thomas's results to be consistent with Pareto optimality in the household, it would have to be that the marginal effects of income on her willingness to pay for child care were much stronger than those of her husband.)

\section{Testing the hypothesis of Pareto Efficiency}

Chiappori (1988), (1992) points out that a cooperative Nash solution with divorce as the threat point is not the only alternative to the unitary hypothesis of family decision-making even if the assumption of Pareto efficiency within households is maintained. Moreover is by no means obvious that the outcomes within families must be Pareto optimal. Chiappori proposes to test the weaker hypothesis that a family chooses some efficient poin on the household utility possibility frontier, using only data on household aggregate consumption. He studies a model in which each member of a maried couple consumes to be "price-takers" both in the goods market and the labor market and are free to work as many hours as they choose. Household aggregate demand is therefore formally the same as aggregate demand in a competitive economy with two consumers and three commodities. According to Diewert (1977), competitive equilibrium in an economy with more commodities than consumers must obey certain empirically falsifiable restrictions. In his 1988 paper, Chiappori (1988) spells out Diewert's restrictions as applied to his two-consumer, threecommodity model, both in parametric form and in a non-parametric, revealed-preference form.

Thomas's results, as well as those of Schultz and of Browning et al tend to reject the hypothesis that household allocations are invariant to household income distribution, but they do not provide direct evidence about whether households are acting efficiently. However, the dramatic difference that Thomas finds in the effect of wife's and husband's income on child welfare leads one to wonder whether for many families, expenditure on children is determined by an inefficient, noncooperative equilibrium in which the wife is the only contributor to the public good, child welfare. (See Bergstrom, Blume and Varian (1986).

\section{Noncooperative Bargaining Theory}

The Nash cooperative solution solution predicts that the outcome of a static, two-person bargaining game will be the outcome that maximizes the product of the two persons' utility gains over the threat point that would obtain in the absence of disagreement. But even if one is willing to accept a Nash cooperative bargaining model of marriage, the appropriate threat point is not obvious. Should the threat point be divorce as in Mansur, Brown, McElroy and Horney? Should it be an uncooperative marriage in which spouses revert to socially sanctioned gender roles for uncooperative spouses as in Lundberg and Pollak? If 
either party to a marriage has the right to divorce the other, should the threat point for each person be the maximum of his or her utility from divorce and from a noncooperative marriage?

The Nash axioms are of no direct help in deciding the appropriate threat point in specific models. But recent work on the noncooperative foundations of bargaining theory offers useful guidance on this question. Ariel Rubinstein (1982) developed an extensive form multi-period bargaining game for two agents in which a cake is to be partitioned only after the players reach agreement. Players alternate in proposing how to divide the cake with one time period elapsing between each offer. Both agents are impatient. The utility to player $i$ of receiving $w$ units of cake in period $t$ is $w \delta_{i}^{t}$. Rubinstein proved that in the limit as the time between proposals becomes small, the only subgame perfect equilibrium is for the cake to be divided in the first period with player $i$ 's share of the cake being $\alpha_{i}=\delta_{i} /\left(\delta_{1}+\delta_{2}\right)$. More generally, if agent $i$ 's utility from receiving $w_{i}$ units of cake in period $t$ is $u_{i}\left(w_{i}\right) \delta_{i}^{t}$ where $u_{i}$ is a concave function, then the only perfect equilibrium is the allocation that maximizes the "generalized Nash product", $u_{1}^{\alpha_{1}} u_{2}^{\alpha_{2}}$ on the utility possibility set $\left\{u_{1}(w), u_{2}(1-w) \mid 0 \leq w \leq 1\right\}$. In case the two agents have equal discount rates, this outcome is the same as the symmetric Nash equilibrium where the threat point is $(0,0)$.

Binmore (1985) shows how the Rubinstein model can be extended to the case where each of the bargaining agents has access to an "outside option". Binmore's model is like the Rubinstein model, except that each agent $i$ has the option of breaking off negotiations at any time and receiving a payoff of $m_{i}$ units of cake, in which case the other player receives no cake. Given that the outcome in the game without outside options is the same as the Nash cooperative equilibrium with threat point $(0,0)$, one might conjecture that the effect of the outside options would be to move the threat point to $\left(m_{1}, m_{2}\right)$. (If negative values of $m_{i}$ are considered, this conjecture might be amended to $\left(\max \left\{0, m_{1}\right\}, \max \left\{0, m_{2}\right\}\right)$. Binmore demonstrates, that this is not the answer. Instead, it turns out that the only perfect equilibrium for the game with outside options is an agreement in the first period on the utility distribution $\left(u_{1}, u_{2}\right)$ that maximizes the Nash product $u_{1}^{\alpha_{1}} u_{2}^{\alpha_{2}}$ on the utility possibility set $\left\{u_{1}(w), u_{2}(1-w) \mid 0 \leq w \leq 1\right\}$ subject to the constraint that $u_{i} \geq m_{i}$ for each $i$. In general, this solution is not the same as maximizing $\left(u_{1}-m_{1}\right)^{\alpha_{1}}\left(u_{2}-m_{2}\right)^{\alpha_{2}}$ on the utility possibility set, which would be the outcome of shifting the threat point to $\left(m_{1}, m_{2}\right)$. A similar argument is made by Sutton (1987) and the argument is presented in more detail in a paper by Binmore, Shaked, and Sutton (1989). In this paper, Binmore, Shaked, and Sutton wherein the authors report on laboratory tests in which subjects were engaged in a Rubinstein bargaining game with outside options. Behavior in this game was much better predicted by the Binmore model than by the competing model in which the outside option is the threat point.

Let us consider an application of these principles to a model of marriage. Consider a married couple who expect to live forever in a stationary environment. For ease of exposition, let us assume that they have identical discount rates and that in any period, the utility possibility frontier is the simplex $\left\{\left(u_{1}, u_{2}\right) \mid u_{1}+u_{2}=1\right\}$. Each spouse has an intertemporal utility function of the form $\sum_{i=1}^{\infty} u_{i} \delta^{t}$. In any period where they do not agree on how to distribute utility, person 1 will get a utility of $b_{1}$ and person 2 will get a utility of $b_{2}$, where $b_{1}+b_{2}=b<1$. If either person asks for a divorce, they will divorce. In this case, spouse 1 will get a utility of $m_{1}$ forever and spouse 2 will get a utility of $m_{2}$ forever, where $m_{1}+m_{2}=m<1$. These last assumptions guarantee that neither disagreement nor divorce is efficient for this couple. As in Rubinstein, the spouses alternate in making offers of feasible utility distributions. Following Binmore's argument, one finds that in the limit as the time between offers approaches zero, the in which the spouses agree immediately to distribute utility in every period in such a way as to maximize the Nash product $\left(u_{1}-b_{1}\right)\left(u_{2}-b_{2}\right)$ subject to $u_{1}+u_{2}=1$ and subject to $u_{i} \geq m_{i}$ for $i=1,2$. Depending on the parameters $m_{i}$ and $b_{i}$, there are three possible types of solution:

(i) Neither of the outside option constraints $u_{i} \geq m_{i}$ is binding. In this case, the outcome is $u_{1}=b_{1}+(1-b) / 2$ and $u_{2}=b_{2}+(1-b) / 2$. Neither outside option is binding if $b_{i}+(1-b) / 2 \geq m_{i}$ for $i=1$ and $i=2$.

(ii) The outside option is binding for person 1, but not for person 2. In this case the solution is $u_{1}=m_{1}$ and $u_{2}=1-m_{1}$. This happens if if $b_{1}+(1-b) / 2<m_{1}$.

(iii) The outside option is binding for person 2 , but not for person 1 . In this case the solution is $u_{2}=m_{2}$ and $u_{1}=1 m-m_{2}$. This happens if $b_{1}+(1-b) / 2<m_{1}$,

The first of these cases corresponds to the Pollak-Lundberg cooperative solution where the threat point is not divorce, but a noncooperative marriage. In the other two cases, the divorce threat is relevant, but notice that the outcome is never the outcome predicated by the Mansur-Brown and McElroy-Horney models. When the divorce threat is relevant, there is not an equal split of the gains from being married rather than divorced. Instead one partner enjoys all of the surplus and the other is indifferent between being divorced and being single.

In the absence of agreement one might expect harsh words and burnt toast until the next offer is made. If the couple were to persist in noncooperative behavior forever, the outcome might be worse for one or both persons than being divorced. But divorce (as we have modelled it) is irrevocable, while a bargaining impasse need last only as long as the time between a rejected offer and acceptance of a counteroffer. So long as the gains from marriage are divided in such a way that both are better off being married than being divorced, a threat of divorce is not credible. But for many divisions of utility, a threat of delayed agreement and a later counterproposal is credible. In fact the Rubinstein theorem tells us that there is only one equilibrium division of utility in which no such threat is credible.

Rubinstein's original bargaining model can be relaxed in the direction of realism with out altering the main results. Binmore (1985) shows that one can relax the assumption that the two parties take turns making offers and that the period between offers is of fixed that the two parties take turns making offers and that the period between offers is of fixed person whose turn it is to make the next offer are randomly determined after every refusal. It is straightforward to add a constant probability of death for each partner without seriously changing the model. On the other hand, stationarity of the model seems to be necessary for Rubinstein's beautifully simple result. This stationarity is lacking in a model 
where children grow up and leave the family and where the probability of death increases with age. It would be useful to know more about the robustness of the Rubinstein results to more realistic models of the family. For the time being, Rubinstein's model and its extensions seem to be "the only game in town" as far as giving us a theoretical basis for distinguishing among plausible alternative bargaining theories of the household.

\section{Household Equilibrium without Perfect Information}

David Roth (1992) develops a model of a potentially long-lived partnership in which the partners do not know with certainty how "good" the partnership will be relative to their outside opportunities. If the partnership were known with certainty to be a "good one", the partners would understand that it will be long-lived and will both invest substantial resources in it. As time passes, the partners learn about the quality of their partnership by observing current and past outcomes. The greater the amount of investment in the partnership, the more likely that good realizations will be offered in each period. The more good realizations that are observed, the more likely the partners are to invest. In the model as formulated by Roth, no matter how much is invested, "bad" partnerships will eventually be discovered to be bad, but some "good" partnerships are dissolved by rational decision-makers because a run of bad luck has led the partners to think that the partnership will not last and hence the partmers do not invest. $R$ interative procedure suggested by dynamic programming which enable him to compute and characterize sequential equilibria for this game.

\section{Theories of the Marriage Market}

\section{III.1. Matching Models}

\section{The Gale-Shapley model}

In a beautiful short paper, David Gale and Lloyd Shapley (1962) introduced the concept of a stable marriage assignment and introduced a "courtship algorithm" that leads to a stable assignment of marriage partners for arbitrary configurations of preference rankings of the opposite sex as possible marriage partners. This model has been extended and developed by several authors. See Roth and Sotomayor (1990) for an excellent survey of this work. Here we follow Roth and Sotomayor in presenting a slightly modified version of Gale and Shapley's model that allows the option of remaining single to persons who don't want anyone who will have them

Consider a population consisting of $n$ men and $p$ women. Each person $i$ in the population is able to rank all members of the opposite sex as possible marriage partners and also to determine which members of the opposite sex he or she would be willing to marry if remaining single were the only alternative. All persons satisfying the latter condition are said to be acceptable to i. A monogamous assignment of marriage partners is said to be stable if no two people of opposite sexes would prefer each other to their assigned partners, if no married person would prefer being single to being married to his or her spouse and if no two single people would prefer being married to each other over being single.

The "men-propose" version of the Gale-Shapley algorithm has each man propose to his favorite woman. Each woman rejects the proposal of any man who is unacceptable to her, and if she receives more than one proposal she rejects the proposal of any but the most preferred of these. To her most preferred suitor she says "maybe". At each step in the procedure, men who have been rejected move to their next choice so long as there are any acceptable women to whom they have not proposed. Women reject proposals from unacceptable men and from any but the best of their current suitors, including any man to whom she said "maybe" on the previous step. The algorithm continues until a step is reached where no man is rejected. At this point, all women marry the last man to whom they said "maybe."

The assignment made by the Gale-Shapley algorithm is in general different depending on whether men or women play the active role in proposing. The difference between these outcomes reveals a remarkable polarity of interest between men and women. When al men and women have strict preference orderings over the opposite sex, the "men-propose" assignment turns out to be at least as good for every man as any other stable marriage assignment and to be at least as bad for every woman as any other stable assignment. least as bad for every man as any other stable assign least as bad for eve stable assignments besides the men-propose and the women-propose assignments. The set of stable assignments has the following lattice property, which Roth and Sotomayor attribute to (Donald Knuth (1976)). For any two stable assignments, the assignment in which each woman is given the man she likes better from the two assignments is also a stable assigment. Since both original assignments were stable, it can be shown that the assignment in which each woman gets her preferred man from the two original assignments is the same as the assignment where each man gets his least preferred partner from these two assignments. This polarity of interest is further developed by Roth and Sotomayor (pp 44-46) who show that either adding more women to the marriage market or enlarging some women's lists of acceptable men will (if it has any effect at all) help some men and harm no men and harm some women and help no women.

\section{The Linear Programming Assignment Problem}

Lloyd Shapley and Martin Shubik (1972) and Becker (1974) suggest that the market for marital partners can be posed formally as the classic linear programming assignment prob. lem. The assignment problem is one of the early showcase applications of linear programming techniques (Danzig (1951). Not only does linear programming offer powerfu algorithms for finding an optimal assignment. It also yields dual variables which can serve as "shadow prices" to guide decentralized implementation of the optimum as a market solution.

Tjalling Koopmans and Martin Beckmann (1957) developed the assignment problem as an economic tool. Their model has workers and $n$ jobs. Each worker can be assigned 
to one and only one job. The value of output from worker $i$ in job $j$ would be a specified amount, $a_{i j}$. An efficient assignment maximizes the total value of output from all workers subject to the constraint that each worker can only have one job and each job can only be done by one worker. The dual solution to this linear program yields a vector of wages for workers and of rents for jobs such that if the solution assigns worker $i$ to job $j$, then the wage of $i$ plus the rent of $j$ equals the value $a_{i j}$ of output when $i$ does job $j$. In this solution it turns out that if the "owner" of job $j$ acts as residual claimant in the sense that he pays the equilibrium wage $w_{k}$ to any worker $k$ that he "hires" and receives the net payoff $a_{i k}-w_{k}$, his return is maximized if he hires $i$ where $i$ is the worker assigned to job $j$ by the maximization problem. Likewise, if worker $i$ were the residual claimant after paying the equilibrium rent $r_{k}$ to the "owner" of any job that he took, he would maximize his return by taking the job $t$

The Koopmans-Beckmann model can be interpreted as a problem in optimal marriage assignments, where one sex plays the formal role of workers and the other the role of firms. For each male, $i$, and each female, $j$, there is a number $a_{i j}$ which measures the amount of "marital bliss" that would be produced if $i$ married $j$. Each male is only allowed to marry one female and each female is only allowed to marry one male. The solution to marry one female and each female is only allowed to marry one male. The solution to
the assignment problem determines not only who is assigned to whom in but also how the jointly produced marital bliss is "divided" between the partners of the marriages that form. This division is determined by the "prices" in the dual linear program, just as wages and rents are found in the Koopmans-Beckman interpretation.

Shapley and Shubik develop the game-theoretic interpretation of the assignment model of marriage. They observe that the "core" or equivalently the "set of stable marriage assignments" in a marriage assignment game with transferable utility consists of the (generically unique) assignment of partners that solves solves the linear programming problem and any division of utility among the marriage partners such that the equilbrium utilities of each individual are dual variables for the optimization problem. Shapley and Shubik show that the set of stable marriage assignments has the same polarity between the interests of the sexes as the Gale-Shapley model. There is a "male-best" stable assignment and a "female-best" stable assignment. In the male-best (female-best) assignment, each male (female) is at least as well off as he (she) is in any other stable assignment. The set of stable assignments also shares the lattice property that was discussed for the Gale-Shapley algorithm.

\section{Assignments with and without transferable utility}

The special ingredient that makes it possible to pose marriage as an assignment problem is transferable utility. The interpretation of marriage as an assignment problem has it that for each male, $i$, and female, $j$, there is a number $a_{i j}$ such that if $i$ marries $j$ they will produce $a_{i j}$ units of "bliss" which can be divided between them in any way such that the sum of $i^{\prime} \mathrm{s}$ bliss and $j^{\prime}$ s bliss is $a_{i j}$. On the face of it, the assumption that the total utility from a marriage could be redistributed between the partners just like money or jelly beans seems crude and unreasonable. But the generic model of a household with transferable utility presented in Section I.4 allows quite interesting and subtle interactions between partners within a framework where there is transferable utility.

The Gale-Shapley model is at the opposite extreme from transferable utility. The model contains no allowance for altering the terms of marriage. Since there are no "sidepayments", the utility possibility frontier available to any two potential spouses is just a single point. If it is possible for potential marriage partners to draw up premarital contracts which determine in advance the household's choice of public goods and division of private goods, then the Gale-Shapley model is very unrealistic. But if credible and binding premarital contracts are not possible then, as we will see, there are reasonable models in which the relevant part of the utility possibility frontier for any pair is a single point.

Vincent Crawford and Elsie Knoer (1981) present an ingenious extension of the GaleShapley algorithm that works when monetary side-payments can be made but which does not require transferable utility. ${ }^{15}$ In their model side-payments are measured in discrete units. The options that individuals rank are described both by who the potential mate is and how large the promised side-payment will be. In the initial round, the side-payment of each member of the proposing sex is restricted to a low level. Proposals, refusals and maybes proceed as in the Gale-Shapley algorithm, but each time a member of the proposing sex is refused, the side-payment that he is allowed to offer to the refusing individual increases by one unit. This process continues until no proposal is rejected. The outcome is a stable assignment of partners. Gabriella Demange and David Gale show that general models with side-payments but without transferable utility have share the lattice property found for the Gale-Shapley model and for the asssignment model.

Manoru Kaneko (1982) also analyzes general models of "two-sided exchange economies" that include both the Gale-Shapley model and the transferable utility model as well as markets where there are sidepayments without transferable utility. Kaneko shows that for his model the core is non-empty and coincides with the set of competitive equilibria.

Strategic Issues in Stable Matching

Roth and Sotomayor (1990) present several interesting results about the extent to which assignment mechanisms can be manipulated. If marriages were assigned by the GaleShapley algorithm with males proposing to females, then unless there is only one stable matching for the population, there will be at least one woman who will be better off if she misrepresents her preferences. More generally, there exists no stable matching algorithm which would make truth-telling a dominant strategy for all members of the population. In the Gale-Shapley algorithm, with males proposing, it is dominant strategy for the males to reveal their preferences truthfully. In general, a woman would have to have a great deal of information about others' preferences in order to know how to improve her outcome by deceptive play. For example, if each woman knew who her match would be in the womenpropose version of the Gale-Shapley algorithm, there is a strong Nash equilibrium in which each woman declares a man to be unacceptable if she likes him less than the mate that she

15 The Crawford-Knoer results are generalized by Alexander Kelso and Crawford (1982). 
is assigned in the women-propose outcome. This Nash equilibrium yields the assignment that is best for all women among all the stable assignments.

\section{III.2. Bargaining in the Shadow of the Market}

In the bargaining models discussed above, payoffs from being divorced are determined outside the model. For many people who consider divorce, the utility of the divorce option is the utility of forming a second marriage. ${ }^{16}$ The utility of a second marriage must be determined as part of the same theory that determines the distribution of utility within determined as part of the same theory that determines the distribution of utility within
all marriages. Sharon Rochford (1985) defines an equilibrium of this kind, which she calls a symmetrically pairwise-bargained allocation (SPB). Rochford's model has transferable utility within households. She defines defines an SPB to be an assignment of partners and an allocation of payoffs within marriages such that the division of utility within each marriage is determined by bargaining, where the threat point is determined by the utility each spouse would get from divorce and remarriage. A person's threat point in a marriage is the highest utility that he or she could achieve as a Nash cooperative solution in some other marriage where the threat points in the other marriage are the utilities the two hypothetical partners get in their current marriages. Rochford proposes an interative process that is guaranteed to converge to an SPB. Benny Moldevanu (1992) considers a model of trading partners and formulates an equilibrium concept similar to Rochford's. $\mathrm{He}$ is able to extend her results to economies without transferable utility.

The models proposed by Rochford and by Moldevanu do not include explicit costs of divorce. While the costs of switching from one partner to another may be small for trading partners, this is not likely to be the case for marriage partners, who are likely to have invested significant amounts of "marriage-specific capital" that will be lost if they have invested significant amounts of "marriage-specific capital" that will be lost if they
divorce. If the partners have children, then arrangements for sharing the costs and joys of divorce. If the partners have children, then arrangements for sharing the costs and joys of
child care become difficult and inefficient. ${ }^{17}$ In societies where divorce is unusual, divorced people are sometimes ostracized or at least suspected of being unusually difficult to live with.

The introduction of costs of divorce will markedly affect the workings of the formal model. As Moldevanu points out, in a model like Rochford's, if each person has at least one "clone", then any core allocation, including the symmetrically pairwise-bargained allocations would have the property that identical people must be equally well off. In this case, the SPB allows no scope for bargaining within households. In equilibrium, each ple would correspond equilibrium. In the absence of clones, if there were very close substitutes for each person in the society, spouses would not have much surplus to bargain over, once each is given at

16 Weiss and Willis (1991) report that in a sample taken in 1985 of Americans who had graduated from high school in 1972, about $60 \%$ of those persons who divorced during the period since high school had remarried. 17 See Weiss and Willis (1985) for a discussion of incentive problems that arise for child care in divorce
settlements. least his or her outside option.

Avner Shaked and John Sutton (1984) discuss a model of labor and management which Avelly similar to a model of a marriage in which divorce is costly. In their model the irm has frm has a curcting hese costs by putting a restiction on the timing of offers in a Rubenstein barganing model. This leads to an outcome that is intermediate between a bilateral monopoly outcome wher neither side has an outside option and the "Walrasian" outcome, which would obtain if
there were no costs to a firm from changing its workforce.

Ariel Rubinstein and Asher Wolinsky (1985) have a model of transactions between pairs of agents who meet randomly and bargain if they meet. Their model, if viewed as a model of marriage, suggests an interesting interpretation of the "costs of divorce". They have two types of agents, buyers and sellers. All agents of a given type are identical. At the beginning of each time period, there is a matching stage, where each agent may find a new partner. Some agents will find partners, some will not. If two agents meet, they start to bargain according to a noncooperative iterative bargaining scheme. If the two agents reach agreement, a transaction occurs and they leave the market. If they do not reach agreement in this period, one or both of them might meet another agent of the opposite type who has not agreed to a bargain. If so, the agent ceases bargaining with his or her current bargaining partner and starts bargaining with the newly-met partner. If neither meets a new partner, the current partners proceed to the next round of bargaining between themselves. Aside from the postponement of benefits, a significant cost of not reaching arrent in the possibility that one's current bargaining partner will meet someone else before the next round of offers. If this happens, then one is not will meet someone anybody to bargain with in the next period or even the period after that. sure to meet anybody to bargain with in the next period or even the period after that.
When the number of buyers does not equal the number of sellers, the probability that an When the number of buyers does not equal the number of sellers, the probability that an unattached individual of the scarce type is more likely to meet an eligible trading partner
type than is an unattached individual of the abundant type. This difference is reflected in equilibrium payoffs which award more of the bargaining surplus to the scarce type than to the abundant type.

Binmore's (1985) version of the Rubinstein model with outside options, discussed in the previos section, has strong and interesting implications when there is a transactions cost to anyone who divorces and remarries. To illustrate the workings of this model, consider the special case of a male and female who marry and who reach agreement can achieve any constant flow of utility $\left(u_{m}, u_{f}\right)$ such that $u_{m}+u_{f}=1$. Utilities are normalized so that the utility flow while the partners are in disagreement is 0 for each. At any stage in the bargaining process, either spouse can either accept the other person's offer, reject the other person's offer and make a counteroffer, or ask for a divorce. If the two spouses have equal time rates of discount, then in equilibrium, then according to Binmore's results, the outcome will be an allocation of utility $\left(u_{m}, u_{f}\right)$ that maximizes the Nash product $u_{m} u_{f}$ subject to the constraints that $u_{m}+u_{f}=1$, and that each person gets a utility at least as high as his or her outside option. The utility distribution $\left(\bar{u}_{m}, \bar{u}_{f}\right)=(1 / 2,1 / 2)$ maximizes $u_{m} u_{f}$ subject to $u_{m}+u_{f}=1$. The utilities of the outside option, divorce, to the male and female are 
respectively, $\bar{u}_{m}-c_{m}<\bar{u}_{m}$ and $\bar{u}_{f}-c_{f}<\bar{u}_{f}$. So long as divorce costs are positive to both parties, the presence of the outside option does not influence the bargaining outcome.

In this model, unlike in the Rubinstein-Wolinsky model, the distribution of utility within marriages does not depend on the relative supplies of males and females, but only on their impatience and on the position of the utility possibility frontier relative to the noncooperative outcome within marriage. The difference seems to lie in the fact that in the Rubinstein-Wolinsky model, an individual who "meets a stranger" of the opposite sex can abandon his or her spouse without bearing any transaction cost (though the abandoned spouse may be in for a long wait before another offer appears.) In the variant of the Binmore model just proposed, a threat by either party to abandon the current marriage is not credible because persons who divorce would have to pay the transactions cost of divorce and remarriage and when they are done with this, would be in no better bargaining situation than they were before divorcing. These ideas can readily be extended to a community with many types of males and females and very general utility possibility frontiers within each possible marriage.

When there are divorce costs to both parties, the Binmore argument implies the striking conclusion that even though technology and preferences allow transferable utility, the nature of bargaining determines that there is only one possible distribution of utility between any two people if they should marry. This outcome is the Nash cooperative solution with uncooperative marriage as the threat point. Despite the presence of sidepayments and the availability of remarriage as an outside option, the original Gale-Shapley model without sidepayments then applies. This means that the marriage market suffers from rigidity of a "price" which may be important for clearing the marriage market. If it were possible to settle the distribution of utility within possible marriages in advance by a binding contract, then the distribution of utility between males and females within marriages would respond to competitive forces in such a way as to tend to equilibrate the number of males and the number of females who choose to marry at any time. If, on the other hand, the distribution of utility within marriages is determined by a threat point such as uncoooperative marriage, which is independent of market forces, then changes in the terms of marriage can not be expected to equalize imbalances in supplies of the two sexes in the marriage market.

\section{III.3. Age at Marriage}

\section{Classical One-Sex Population Theory}

Classical Stable Population Theory, as developed by Albert Lotka (1922), predicts shows that if current age-specific fertility and mortality rates for females remain unchanged, then in the long run, the age distribution of the population would asymptotically approach some constant distribution, and accordingly birth rates and population growth rates would approach constancy. In principle, this projection technique could be applied in the same way to male age-specific fertility and mortality. In general applying this one-sex model to males leads to very different predictions than applying it to females. For example, using
1968 data for U.S. males and females predicted respectively, long term population growth rates of 10.1 and 5.7 per 1,000 population. (Prithwis Das Gupta (1973).) Since every child that is born, must have exactly one mother and one father, it must be that given the age distribution of persons of the two sexes in 1968, it was simply not possible for both sexes to maintain constant fertility and mortality rates. A similar logical difficulty arises if one wishes to predict future marriage rates of males and of females separately by projecting current age and sex specific marriage rates into the future.

\section{Two-Sex Theories of Mating}

Modern demographers (Nathan Keyfitz (1971), Das Gupta (1973)) have responded to this discrepancy by building two-sex models based on "marriage functions" which ensure the necessary parity between male and female parents or wedding partners. As applied to marriages, these models predict that the number of marriages between a female of age $i$ and a male of age $j$ in year $t$ should depend at least on the number of males and the number of females present in year $t$. David McFarland (1972) these models because they these possibilities, the number of marriages between a female of age $i$ and a male of age $j$ should depend on the numbers of males and females of other ages in the population as well. McFarland suggests an iterative procedure (which bears an interesting similarity to the Gale-Shapley model) for dealing with these effects.

Pollak $(1985,1986,1987)$ reformulates the "two-sex problem" by replacing the constant age-specific fertility schedule of the classical theory with two more fundamental relationships. These are a "birth matrix" and a "mating rule." The birth matrix postulates an expected number of births per period from a marriage of an age $i$ male to an age $j$ female. The mating rule is a function that determines the number of marriages of type $i$ males to type $j$ females for all $i$ and $j$ as a function of the vector listing the numbers of males and females of each age and sex in the population. Pollak shows that if these relationship remain constant over time and if the mating rule follows certain natural conditions, the dynamical system so defined will converge to a constant equilibrium growth rate, yielding a constant equilibrium age structure. Pollak imposes only certain very general conditions on the mating function such as nonnegativity, homogeneity, continuity, and that the number of persons of a given sex who marry must not exceed the number of persons of that age and sex in the population.

Pollak's mating rule is a "reduced form" description of the dependence on the outcome of a marriage market on supplies and demands of the two sexes from various cohorts. Bergstrom and Lam (1989a, 1989b) construct a simple, empirically-implementable model of the marriage market that rationalizes Pollak's mating rule. In the simplest version of the Bergstrom-Lam model, individuals do not care who they marry, but only when they marry. Each person has a utility function $U_{i}\left(C_{i}, A_{i}\right)$, where $C_{i}$ is the amount of private goods that person $i$ consumes and $A_{i}$ is person $i$ 's age at marriage. If persons $i$ and $j$ marry each other, then they must marry on the same day. Their choice of wedding date is a "household public good" which simultaneously determines both of their ages at marriage. In the absence of side payments, two arbitrarily selected persons will disagree about their 
preferred wedding date if they were to marry. Suppose, for example that all males prefer marrying at age 25 and all females prefer marrying at age 23 . A male and a female will agree about the best time for two of them to marry only if the male was born two years earlier than the female. But in a population where cohort sizes change over time, there will not always be an equality between the number of females of one cohort and the number of males of a cohort born two years earlier. If males prefer to marry at an older age than do females, then if there is a "baby boom", females in the boom generation will find a shortage of males who want to marry when they do, while the birth rate falls temporarily, males will find a shortage of females who want to marry when they do. One expects that when members of some sex and some cohort are in excess supply relative to their "natural partners", there will be readjustments in which some of the abundant group postpone marriage and some of the scarce group marry earlier than they otherwise would. A linear programming assignment model of marriage illustrates just how this would work.

\section{A Marriage Market Theory of Age at Marriage}

To make this model empirically implementable, Bergstrom and Lam study a model in which utility functions are linear in consumption and quadratic in age at marriage. A person who is born in year $b_{i}$ and married in year $d_{i}$ will be married at age $d_{i}-b_{i}$. If this individual's preferred age of marriage is $\bar{a}_{i}$, then his or her utility can be represented by $u_{i}\left(c_{i}, d_{i}, b_{i}\right)=c_{i}+\left(\left(d_{i}-b_{i}\right)-\bar{a}_{i}\right)^{2}$. If male $i$ and female $j$ marry, they will have to choose the same date of marriage, so the date of marriage is formally a "household public good" . The assumption of quasilinear utility implies that for any male and female who consider marrying, there is a unique Pareto efficient date of marriage. Suppose, for example, that all males prefer to marry at age $\bar{a}_{m}$ and all females prefer to marry at age $\bar{a}_{f}$ and suppose that each person $i$ has a fixed initial endowment $W_{i}$ of wealth. Then the utility possibility frontier for male $i$ and female $j$ if they should marry is given the equation

$$
u_{i}+u_{j}=W_{i}+W_{j}+\max _{d}\left\{\left(d-b_{i}-\bar{a}_{m}\right)^{2}+\left(d-b_{i}-\bar{a}_{f}\right)^{2}\right\} .
$$

This expression is maximized when their wedding date is half way between the preferred wedding dates of the two individuals. That is, $d=\left(b_{i}+a_{m}\right) / 2+\left(b_{j}+a_{f}\right) / 2$. The total utility achieved by the two individuals is then $a_{i} j=W_{i}+W_{j}+\left(\left(b_{i}+a_{m}\right)-\left(b_{j}+a_{f}\right)\right)^{2} / 2$. These $a_{i} j$ 's are the appropriate entries in the payoff matrix for the linear programming assignment problem.

Suppose that the numbers of males and females born in year $i$ who survive to marriage age are $M_{i}$ and $F_{i}$ respectively and let $X_{i j}$ be the number of males born in year $i$ who marry females born in year $j$. Then the solution to the assignment problem is an assigmnent that maximizes $\sum a_{i j} X_{i j}$ subject to $\sum_{i} X_{i j}=F_{j}$ for all $j$ and $\sum_{j} X_{i} j=M_{i}$ for all $i$. In the special case where all males have the same initial wealth $W_{m}$ and all females have the same initial wealth $W_{f}$ the total utility $a_{i} j$ from a marriage between a male born in year $b_{i}$ and a female born in year $b_{j}$ is $W_{m}+W_{f}+\left(\left(b_{i}+a_{m}\right)-\left(b_{j}+a_{f}\right)\right)^{2} / 2$. If one knows the preferred ages of marriage, $a_{m}$ and $a_{f}$, then this model specifies the full $a_{i} j$ matrix and will therefore predict future marriage rates for both sexes given the number of persons of each sex and vintage. Conversely, using historical data one can find the choices of parameters $\bar{a}_{m}$ and $\bar{a}_{f}$ that best fit the data. More flexible functional forms and some variation of preferences among individuals can be accommodated within this model, in fairly obvious ways. The parameters of such models can be fit using historical data. Bergstrom and Lam (1989a) applied this technique to Swedish historical data on marriage rates.

\section{Why do Women Marry Older Men?}

One of the strongest of demographic regularities is the observation that men marry later in life than females. In a study conducted by the United Nations, ${ }^{18}$ the average age of marriage for males exceeded that for females in each of 90 countries and in every time marriage for males exceeded that for females in each of 1950 and 1985 . The age difference tends to be larger in tradiperiod studied between 1950 and 1985 . The age difference tends to be larger in traditional societies than
industrial countries.

Mark Bagnoli and Ted Bergstrom (1993) proposed an explanation for this difference. Thark for their ability to bear children and manage a household, while men are valued for their ability to make money. Information about how well a male will perform economicallywhether he is diligent and sober-becomes available at a later age than the relevant information about how well a female would perform her household roles. This leads to an "intertemporal lemons model", in which males who do not expect to do poorly in later life will seek to marry at a relatively young age and males who expect to prosper will postpone marriage until their success becomes evident to potential marriage partners. Females, on the other hand, marry relatively early, with more desirable females marrying the successful, older males who postponed marriage and the less desirable females marrying the young males who want to marry young. In equilibrium, a young male who attempts to marry is signaling a lack of confidence in his future economic prospects. While the most desirable fernales would not accept such males, the less desirable females have no better alternatives in the marriage market and hence are willing to marry young males.

This theory implies not only that males tend to marry later in life than females, but also that males who marry young. will tend to be less prosperous in later life than males who postpone marriage. Bergstrom and Robert Schoeni (1992) investigate the empirical relationship betwee and for females. plot wage income of males in later life as a function of the age at which they married. Income is highest for those who marry in their late 20's. Men who marry at age 28 or 29 have average earnings about $20 \%$ higher than men who marry at 18.

\section{Interdependent Preferences Within Families}

\section{IV.1. Benevolence and other Forms of Unselfishness}

18 Patterns of First Marriage: Timing and Prevalence (1990). 


\section{Preferences on Allocations}

If household members love each other, copy each other, envy each other or annoy each other, then an individual's preferences depend not only on his own consumption, but also on the consumptions of other family members. When individual preferences are defined over the entire allocation of goods in the family, each individual's consumption of each good becomes a household public good, since in principle, all household members may care about any person's consumption of any good.

For a household with $h$ household members, $n$ private goods and $m$ public goods, let $x_{i} \in R^{n}$ be the vector of private goods consumed by family member $i$ and let $y \in R^{m}$ be the vector of household public goods. Each household member $i$ has a utility function of the form $U_{i}\left(x_{1}, \ldots, x_{n}, y\right)$. Let $T \subset R^{n+m}$ be the set of all the aggregate allocations $(x, y)$ that are feasible for the household. This model of preferences is equivalent to a model with $h n+m$ public goods and no private goods in which the $h n$ of the public goods are amounts of commodity $i$ for person $j$ for $i=1, \ldots, n, j=1 \ldots, h .^{19}$ Since private goods are exchangeable between persons, the set of feasible allocations for the household is the set $\left\{\left(x_{1}, \ldots, x_{n}, y\right) \mid\left(\sum_{i} x_{i}, y\right) \in T\right\}$. If all private goods and household public goods are purchasable at market price vectors $p$ for private goods and $q$ for public goods, and if total income of household members is $M$, then $T=\{(x, y) \geq 0 \mid p x+q y \leq M\}$.

Between the general formulation of interdependent preferences with no special structure and the polar case of purely selfish preferences, lie some interesting intermediate cases. Bergstrom (1970) (1971) suggests that the assumption of "weak separability" of preferences between individuals be used in defining nonmalevolent and benevolent preferences. 20 Where there are public and private goods in the family, we define person $i$ 's preferences to be separable with respect to $j$ 's consumption if

$$
U_{i}\left(x_{1}, \ldots, x_{j}, \ldots, x_{h}, y\right) \geq U_{i}\left(x_{1}, \ldots, x_{j}^{\prime}, \ldots, x_{h}, y\right)
$$

for some allocation $\left(x_{1}, \ldots, x_{n}, y\right)$ implies that

$$
U_{i}\left(x_{1}^{\prime}, \ldots, x_{j}^{\prime}, \ldots, x_{h}^{\prime}, y\right) \geq U_{i}\left(x_{1}^{\prime}, \ldots, x_{j}^{\prime}, \ldots, x_{h}^{\prime}, y\right)
$$

for every allocation $\left(x_{1}^{\prime}, \ldots, x_{h}^{\prime}, y\right)$.

The assumption consumer $i$ 's preferences are separable with respect to $i$ 's own consumption means that $i$ 's preferences among alternative bundles $\left(x_{i}, y\right)$ of private goods and household public goods are not changed by changes in the consumption bundles of others. In this case, a person may care about what other family members consume, but the consumption of other family members does not affect one's preferences among bundles for oneself. In this case, each individual $i$ has a well-defined "private utility function" $v_{i}\left(x_{i}, y\right)$

19 This notation can be used even where some household members do not care about the consumption of some or all goods by some or all other members.

20 A thorough treatment of alternative separability assumptions and their implications for the functional form of utility is found in Blackorby, Primont and Russell (1978). such that $v_{i}\left(x_{i}, y\right)=U_{i}\left(x_{1}^{\prime}, \ldots, x_{i}, \ldots x_{h}^{\prime}, y\right)$ regardless of what values are chosen for $x_{j}^{\prime}$ for $j \neq i$.

Given the separability assumptions that allow a definition of private utility functions, it is natural to define benevolent preferences to be those in which each person favors any change in allocations that increases the private utility of some family members without lowering the private utility of others. If this is the case, then preferences of every person $i$ can be represented by a utility function of the Bergson-Samuelson form,

$$
U_{i}\left(v_{1}\left(x_{1}, y\right), \ldots, v_{h}\left(x_{h}, y\right)\right) \text {. }
$$

Where preferences are representable in the Bergson-Samuelson form, Sidney Winter (1969) and Bergstrom (1970) define preferences of consumer $i$ to be benevolent (non-malevolent) toward $j$ if $U_{i}$ is an increasing (non-decreasing) function of $v_{j}$. G. C. Archibald and David Donaldson (1976) define preferences of the Bergson-Samuelson form to be nonpaternalistic preferences. They point out that non-paternalistic preferences permit not only non-malevolence and benevolence, but also malevolence as well as various types of preferences for equity which may cause $U_{i}$ to be a non-monotonic function in some or all preferences for eq
of its arguments.

\section{IV.2. Interdependent Utility Functions}

When family members love (or hate or envy) each other, their individual happiness and sorrows can be intricately interwoven and the interdependent happiness or unhappiness of individuals who care about each other can feed on itself. When happiness is interdependent, the properties of preferences over allocations must be deduced from a more fundamental theory of interdependent utilities. The problem of disentangling these interrelated preferences in order to study the derived preferences on allocations has been addressed by several economists, including Bergstrom $(1971,1988,1989)$, Robert Barro (1974), Becker (1974), David Pearce (1983), Doug Bernheim and Oded Stark (1988). The model described here is taken from Bergstrom (1989). Let $c_{i}(t)$ be family member $i$ 's consumption bundle, and let $V_{\sim i}(t)$ be the vector of utility levels of all family members other than $i$ as perceived by $i$ at time $t$. Then consumer $i$ 's utility level is given by

$$
\left.U_{i}(t)=F_{i}\left(u_{i}\left(c_{i}(t)\right), V_{\sim i}(t)\right)\right)
$$

where the function $u_{i}\left(c_{i}\right)$ represents person $i$ 's "private preferences" over commodity bundles. Suppose that family members can assess each others' happiness, but with a lag, so that for all $i$ and $t, V_{\sim i}(t)=U_{\sim i}(t-1)$. Then for given initial utility levels, the utility levels of each person in each period are determined by the system of difference equations $\left.U_{i}(t)=F_{i}\left(u_{i}\left(c_{i}(t)\right), U_{\sim i}(t-1)\right)\right)$. For any fixed consumption allocation, $\left(c_{1}, \ldots, c_{n}\right)$, an equilibrium for this system is a solution to the system of simultaneous equations

$$
U_{i}=F_{i}\left(u_{i}\left(c_{i}\right), U_{\sim i}\right)
$$

In order to deal with the economic choices made by family members, we must convert this system of interconnected utility functions into a system of independent utility functions 
defined over consumption allocations. For expositional convenience, let the functions $F_{i}$ be additively separable, ${ }^{21}$ so that the system of utility functions takes the special form

$$
U_{i}(t)=u_{i}\left(c_{i}(t)\right)+\sum_{j \neq i} a_{i j} U_{j}(t-1) .
$$

This system of difference equations can be written as a matrix equation $U(t)=u(c(t))+$ $A U(t-1)$, where $u(c(t))$ is the column vector whose ith component is $u_{i}\left(c_{i}(t)\right), U(t)$ is the vector of utilities of family members at time $t$ and $A$ is the matrix with zeros on the diagonal and where $A_{i j}=a_{i j}$ for $i \neq j$. If $(I-A)^{-1}$ exists, then for a fixed allocation $c$, there is a unique equilibrium vector of utilities $U(c)=(I-A)^{-1} u(c)$, expressing preferences over allocations. The system of difference equations determining $U(t)$ will be stable if and only if the eigenvalues of the matrix $A$ all have absolute values less than 1.

As Pearce (1983), and Bergstrom (1988) observe, when utility interdependence is benevolent, the matrix $A_{i j}$ is non-negative and the formal structure of the model is the same as that of Leontief input-output matrices. The theory of productive Leontief matrices (See David Gale (1960)) can be borrowed to good effect. A non-negative matrix $A$ is said to be productive if there exists some positive vector $x$ such that $(I-A) x$ is a strictly positive vector. Gale shows that when this condition is satisfied:

i The matrix $(I-A)^{-1}$ exists and is non-negative in every element.

ii All eigenvalues of $A$ are smaller than 1 in absolute value.

In the model of utility interdependence, the matrix $A$ will be a productive matrix if (in the absence of constraints on available resources) there would be some way to increase the utilities $U_{i}$ of each $i$ by increasing the the "private utility" $u_{i}$ of each $i$. If this is the case, if the allocation of consumption is a constant vector $c$, the system of difference equations above converges to a unique solution $U$ where $U_{i}=\sum_{j} b_{i j} u_{j}\left(c_{j}\right)$ and where the weights $b_{i j}$ are all non-negative.

The requirement that $A$ be a productive matrix limits the strength of benevolent in terdependence. For example, in a two-person family, $A$ will be a productive matrix if and only if $a_{12} a_{21}<1$. Bergstrom (1971), (1989) shows that for two persons, a system of superbenevolent interdependent utilities in which $a_{12} a_{21}>1$ has the property that at all Pareto optimal allocations, disagreements between the two persons take the form of each wanting the other to have the better part. ${ }^{22}$

\section{IV.3. Intergenerational Utility Interdependence}

Utility interdependence in families does not begin and end with a single nuclear family.

21 If these functions are not additively separable, we find similar results at least locally by appealing to the implicit function theorem in the obvious way.

22 Rosa Motzkin and Peter Streufert (1991) present an interesting example in which supermalevolence leads to paradoxes similar to those induced by superbenevolence.
Everyone's parents were children of parents who were children of parents and so on. ${ }^{23}$ Samuelson (1958) pioneered formal modelling of an "overlapping generations" economy in which a new generation appears in every time period, and each generation ages and dies. In Samuelson's model, there is no benevolence between parents and offspring. Each dies. In Same the model, there is no bener newbon encounters with preceding and subsequent generations are entirely commercial-borrowing or lending to smooth her lifetime consumption. ${ }^{24}$

Robert Strotz (1955) argues that individual preferences need not be time-consistent in the sense that if one makes a lifetime consumption plan that is optimal from the viewpoint of the present, one's "future self" may choose not to abide by this plan. In the absence of time-consistency, Strotz (1955) suggests two possible theories of consumer behavior. These theories, which are clarified and refined by Pollak (1968) and by Blackorby, Primont and Russell (1978), are known as theories of "naive" strategies and of "sophisticated" strategies. A person with a naive strategy takes the first step of the intertemporal consumption plan to an equilibrium of sophisticated strategies, a person with intertemporally inconsistent plans chooses his current consumption, knowing that in the next period, his preferences over the future will not be consistent with his current preferences. If he knows what these preferences will be, then in equilibrium, each period's choice will be optimal for that period based on what he knows will be chosen in future periods.

As Edwin Phelps and Robert Pollak (1968) and Blackorby, Primont and Russell (1978) suggest, the Strotz model is a natural starting point for a theory of the economic interaction between benevolent parents and their descendants. With this interpretation, let $c_{t}$ be the consumption vector of generation $t$ and ${ }_{t} c$ be the vector $\left(c_{t}, c_{t+1}, \ldots\right)$ specifying the consumption of generation $t$ and each subsequent generation. Then the utility function a person in generation $t$ has preferences represented by a utility function of the form $U_{t}\left({ }_{t} c\right)$. The Strotz model applied to this situation would allow a member of any generation $t$ to choose its own $c_{t}$ and to leave an inheritance to its successor generation. The next generation in turn is allowed to choose its consumption and the inheritance it leaves to its successor. A mother who follows a naive strategy chooses consumption and saving based on the (generally incorrect) assumption that her descendants will dispose of her inheritance Al incer who follows a sophisticated strategy chooses her preferred amount of saving in the knowledge that her daughter will spend her inheritance in a way that is optimal from the daughter's point of view.

Tjalling Koopmans(1965), (1972) studied conditions on utility functions that guarantee

${ }^{23}$ It is tempting to say that every child will be a parent of children who will be parents, but of of course not everyone has children. Most economic models of overlapping generations do not, however, take this

24 Peter Diamond (1965) extends this model to allow accumulation of capital and to study the effects of national debt. 
time-consistency. Where ${ }_{t} c$ is the vector $c_{t}, \ldots, c_{m}$ of consumption in time periods from $t$ until the end of the decision-maker's life, Koopmans showed that if preferences are additively separable between time periods and time consistent, then (subject to some techical conditions) it must be that preferences of the individual in time $t$ are representable by $a$ "time-discounted" utility function of the form $U_{t}=\sum_{\tau=t}^{m} \alpha^{r} u\left(c_{r}\right)$. If weak separability rather than additive separability is assumed and if the time horizon is infinite, then utility time consistent utility functions take the recursive form $U_{t}\left({ }_{t} c\right)=V\left(c_{t}, U\left({ }_{t-1} c\right)\right)$.

Naive application of single-person intertemporal models to family dynasties lack one important important feature of modern economic life-the illegality of slavery. It is natural in a single-consumer model to allow the consumer to borrow on future income, even if he is not able to commit his future selves to a particular course of action. In the intergenerational interpretation, people are allowed to leave positive inheritances, but they are not allowed to sell the future labor services of his descendants and thus enhance their current consumption. bequests, saving and debt in models with various assumptions about mating patterns preference differences within families where parents can not extract wealth from their descendants.

One of the most influential applications of recursive intergenerational utility is Robert Barro's (1974) paper, "Are Government Bonds Net Wealth?". Barro argues that if utility functions take the form $U_{t}\left({ }_{t} c\right)=V\left(c_{t}, U\left({ }_{t-1} c\right)\right)$ and if each generation voluntarily leaves an inheritance to its successor, then government programs which impose intergenerational transfers (for example subsidized education, social security, and government debt) will be offset by corresponding changes in inheritance.

Barro finds neutrality in a model where reproduction is asexual or the only mating is between siblings. There are no marriages and no connections between family lines. Kyle Bagwell and Douglas Bernheim (1988) suggest that if Barro's model is to be taken seriously, then it must also apply in a model with intermarriage between families. Bernheim and Bagwell argue if that if a daughter from one family marries a son from another family and for to would in undone by offsetting changes in the inheritances of the two sides of the family. But this is only the beginning. If each member of the young couple has a sibling who marries someone else, then the two families who were directly linked by marriage will be indirectly linked to a third and fourth family, which in turn will be linked to other families. The same argument that shows that directly linked families will offset governmental transfers by changing their gifts applies to indirectly linked families. Bernheim and Bagwell apply simulations and some corroborating arguments from random graph theory to show that with reasonable models of mating, there is a very high probability that any two families in an economy will be linked indirectly by marriage where the links are counted over two generations. If it were the case that for all marriages, both sets of parents-in-law left inheritance to their offspring then with very high probability, almost any small governmental income redistribution would be undo by ofsetting private actions. Bernheim and Bagwell find this implausible and suggest that it is likely that there are large numbers of breaks in the chain, that is instances where one or both sets of parents-in-law do not leave estates to their children. If this is the case, then we can not expect Barro's neutrality result to apply.

Laitner (1991) presents a model in which marriage is not random but strongly assortative on income so that persons who expect large inheritances will marry others who expect similarly large inheritances. In Laitner's model, the cross-sectional neutrality found by Bernheim and Bagwell is absent because marriages between children from families of significantly different income levels are rare and when they do occur, typically the less wealthy parental family will leave no estate to the young couple.

An economically and mathematically interesting structure arises when each generation cares not only about its own consumption and the utility of its successor also about the utility of its parent generation. Miles Kimball (1987), models "two-sided altruism" by assuming that preferences of generation $t$ take the additively separable form:

$$
U_{t}=u_{t}\left(c_{t}\right)+a U_{t-1}+b U_{t+1} \text {. }
$$

Kimball was the first to solve this system of interdependent utility functions for the equivalent set of utilities defined over allocations. Hori and Kanaye (1989) and Hori ((1990) study extensions of the two-sided altruism model to cases where the interaction are of the not non-additively separable form $U_{t}=V\left(U_{t-1}, c_{t}, U_{t+1}\right)$

Bergstrom (1990) studies Kimball's two-sided altruism within a more general class of models where interdependent utilities are expressed by a (denumerable) matrix equation $U=u+A U$ where $A$ is a non-negative matrix. In Kimball's case, the matrix has values $a$ everywhere on the first subdiagonal, $b$ everywhere on the first superdiagonal and zeros (discussed above in Section ??) extends in a natural way to the case of denumerable matrices. ${ }^{25}$ In Kimball's case, the matrix $I-A$ is dominant diagonal if and only if $a+b<1$. If this is the case, then the interdependent utility functions can be untangled to yield utility functions over allocations for each generation. The utility function of a member of generation $t$ takes the form:

$$
U_{t}=\sum_{j=1}^{\infty} \alpha^{j} u_{t-j}\left(c_{t-j}\right)+u_{t}\left(c_{t}\right)+\sum_{j=1}^{\infty} \beta^{j} u_{t+j}\left(c_{t+j}\right)
$$

where $0<\alpha<1,0<\beta<1$ and $\frac{\alpha}{\beta}=\frac{a}{b}$. In particular, $\alpha=\frac{1-\sqrt{1-4 a b}}{2 b}$ and $\beta=\frac{1-\sqrt{1-4 a b}}{2 a}$.

From the above expression it can be seen that with two-sided altruism, each generation agrees with any later generation about the merits of intergenerational transfers between generations coming after the later generation or before the earlier generations, but will in general disagree about income transfers among generations falling in between. It is also interesting to see that in the case of two-sided altruism, even if the current generation

25 While many of the fundamental results of finite dimensional linear algebra carry over to denumerable matrices and vectors, there are some nasty surprises. Among these surprises are the fact that matrix multiplication is not, in general, associative and the fact that a matrix may have more than one inverse (For a good exposition of this theory, see Kemeny et. al. (1900).) Ect

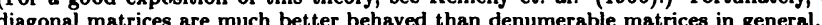


cannot change the consumption of previous generations, an increase in the weight $a$ that a each generation puts on its parent's total utility $U$ results in an increase the the paramete $\beta$ which is the weight that each generation puts on its offspring's private utility $u$.

Laitner (1988) studies gift and bequest behavior in a model of two-sided altruism where bequests must be positive and voluntary and where there are random differences in wealth between generations. As Laitner points out, in the most natural models of intergenerational preferences, there will net gifts from parents to children if the parents are rich enough relative to the children and there will be gifts from children to parents if the children are rich enough relative to the parents. But over some (quite possibly large) intermediate range of relative incomes, parents will not choose to leave estates and children will not choose to make net gifts to their parents. Thus there will be a positive (and possibly high) probability, that within any family line the chain of voluntary gift-giving necessary to sustain neutrality as in the Barro model or the Bernheim-Bagwell model.

\section{IV.4. Pareto Optimality of Competitive Equilibrium in Households with Util-} ity Interdependence-The First Welfare Theorem

In the presence of benevolence, there is in general no reason to expect that competitive equilibrium is Pareto optimal. If we define competitive equilibrium so as to exclude the possibility of gifts, then even in a two-person family a competitive equilibrium can fail to be Pareto optimal. The reason is simply that with benevolence it may be possible for both donor and recipient to benefit from a gift. ${ }^{26}$

The problem in the previous example could be fixed by extending the notion of competitive equilibrium to allow for voluntary "gifts". This approach is taken in Bergstrom (1971), who shows that for two-person families, a competitive gift equilibrium is Pareto optimal. But for households in which more than one person cares about the consumption of others, a competitive gift equilibrium in which individuals decide independently how much to give each other is not Pareto optimal. The reason is that the well-being of someone who is loved by more than one person becomes a "public good". Purely bilateral gift arrangements will not result in a Pareto optimal allocation. In such an environment, Pareto efficiency requires some kind of multilateal coordination among those who are benevolent toward the same individual. Bergstrom (1971) explores a Lindahl equilibrium in which those who are benevolent toward an individual each pay some share of the cost of that individual's consumption and all agree on the quantities, given their cost shares.

In Becker's Rotten Kid model (1974), competitive equilibrium with gifts leads to a Pareto optimal allocation in the household. However, this optimality is purchased with a very strong assumption. In particular it is assumed that there is one benevolent family member who makes voluntary gifts to each of the other family members, while no other

26 For example, consider a family with two persons and one good. Utility functions $U_{i}\left(x_{1}, x_{2}\right)=x_{1}^{2} x_{2}$ and $U_{2}\left(x_{1}, x_{2}\right)=x_{1} x_{2}^{2}$, where $x_{i}$ is the amount of good consumed by person $i$. Person 1 has an initial
endowment of 5 units of the private good and person 2 has 1 unit. The initial endowment $(5,1)$ is a competitive equilibrium, but it is not Pareto optimal, since both persons would prefer the allocation where person 1 gets four units and person 2 gets two units. family members choose to make gifts. Since by assumption, the head of the family is making gifts to all other family members the allocation that results is the household head's favorite allocation among all allocations which cost no more than total family income. ${ }^{27}$

In an overlapping generations model where each generation has a property right to its own labor, the assumption that a current household head is willing to make positive gifts to all future generations is not attractive. But for families in which preferences are characterized by the recursive structure $U_{t}=U_{t}\left(c_{t}, U_{t+1}\right)$, competitive equilibrium with voluntary inheritance turns out to be Pareto optimal even if some generations choose to leave nothing to their successors. I have not seen either a statement or a proof of this proposition in the literature, but for a family with a finite horizon, proving this proposition it is a fairly easy exercise in backward induction. ${ }^{28}$ One uses the recursive structure of preferences to show that if an allocation is at least as good for all family members and preferred by some family members to a competitive equilbrium, then the total cost of the proposed allocation to the family dynasty exceeds the total cost of the family's competitive allocation. The remainder of the proof mimics the Arrow-Debreu proof of the Pareto optimality of competitive equilibrium.

\section{The Efficiency of Competitive Equilibrium with Non-Benevolence}

A plausible conjecture is that the First Welfare Theorem (Competitive equilibrium is Pareto optimal.) applies if preferences are non-benevolent or malevolent. Robert Parks (1991) demonstrates that this conjecture is true for a broed class but not for all nonbenevolent preferences. Where all family members have preferences of the Bergson form

$$
U_{i}\left(v_{1}\left(x_{1}\right) \ldots, v_{n}\left(x_{n}\right)\right) \text {, }
$$

Parks defines the $n$ by $n$ matrix $G\left(v_{1}, \ldots, v_{n}\right)$ to be the Jacobean matrix whose $i j$ th element is $\partial U_{i}\left(v_{1} \ldots, v_{n}\right) / \partial v_{j}$. He shows that a competitive equilibrium will necessarily be a local Pareto optimum if the matrix $G^{-1}$ is a non-negative matrix. ${ }^{29}$ Parks shows that the matrix $G^{-1}$ will be non-negative if the off-diagonal elements of $G$ are non-positive and the diagonal elements are positive and if with a small change in the resource endowment of the economy, it would be possible to make everyone better off. ${ }^{30}$

\footnotetext{
27 Although in the simplest version of the Rotten Kid theorem, family members other than the head are one family member is benevolent if it is assumed that the utility of the head depends positively on the overall utility of each family member.

${ }^{28}$ The proof extends to an infinite horizon if there is sufficient "impatience" so that the present value of resources to appear in the distant future converges to zero.

29 A local Pareto improvement is possible only if $G d v>0$ for some vector $d v$. If $G^{-1}$ is non-negative 作 dv $>0$.

30 Parks' argument is this. If a small change can make everybody better off, then Gdv $>0$ for some vector $d v$. If this is true, $G$ is a dominant diagonal matrix with positive off-diagonals and therefore $G^{-1}$ is a non-negative matrix. McKenzie (1960).
} 
IV.4. Sustainability of Pareto Optimality as Competitive Equilibria-The Second Welfare Theorem

Winter (1969) observed that the Second Welfare Theorem (With convex preferences, every Pareto optimum can be sustained as a competitive equilibrium.) extends without modification to the case of non-malevolent preferences. This result has an interesting application to the theory of family consumption because it suggests that in families where application to the theory of family consumption because it suggests that in families where each family member an allowance to spend on personal consumption.

Winter's result, however, is not quite as powerful as it might first appear. Competitive equilibrium as defined by Winter requires that each family member spend his income only on himself. A more useful theorem for decentralization in a benevolent family would state that in a "competitive equilibrium with gifts", where people are allowed to choose their best combination of personal consumption and money transfers to others, every Pareto optimum is a competitive equilibrium. But this result is not true without some qualification. For example, consider the case where $U_{i}\left(x_{1}, x_{2}\right)=x_{1} x_{2}^{2}$ and $U_{2}\left(x_{1}, x_{2}\right)=x_{1}^{2} x_{2}$ and consider the allocation $(3,3)$, which is Pareto optimal. If no gifts are permitted, then this is a competitive equilibrium, but if gifts are allowed, person 1 would want to give 1 unit to person 2 and accept no gifts from her. If person 2 were allowed to choose, she would give one unit to person 1 and accept nothing from him. Thus there will be no equilibrium in which each is allowed to determine his or her net gift to the other. We could rescue the situation by defining a gift equilibrium to be one in which nobody wants to make a gift which other persons are willing to accept, or alternatively by assuming that persons are "selfish enough" so that it never happens that one person wants to make a gift that the other will not accept. More complicated versions of this problem arise when several generations have interconnected utility functions. See Bergstrom (1971) or Pearce (1983).

Archibald and Donaldson (1976) show that with certain restrictions, the Second Welfare Theorem extends to non-paternalistic preferences which are not monotonic increasing in all of the $v_{j}$ 's. Their argument is based on the observation that the standard first order conditions for Pareto optimality in an economy with non-paternalistic require that individuals all have the same marginal rates of substitution between goods. Given sufficient convexity, and given that the constrained optimality problem determining a Pareto optimum satisfes the appropriate constraint qualifications so that the standard first order conditions are necessary for Pareto optimality, the Archibald-Donaldson conclusion follows.

\section{Public Goods and Benefit-Cost Analysis in Benevolent Families}

If family members want each other to be happy and if they share some household public goods, how do we determine a Pareto efficient expenditure on these public goods? For example, consider a married couple without children who are deciding whether to get a new car. Suppose that the husband is willing to pay $H_{1}$ dollars for the enjoyment he using the car. The wife is willing to pay $W_{1}$ dollars for the enjoyment she would get from using the car and $W_{2}$ dollars for the enjoyment the husband would get from using the car. How much should the couple be willing to pay in total for the car?

In the presence of "pure" nonmalevolence, there is a very simple and perhaps surprising answer to this question. Even though each person is willing to pay something for the other's enjoyment of the car, they should buy the car only if and only if the sum $H_{1}+W_{1}$ is at least as large as the price of the car. This result is a consequence of a very general result which also applies to many-person families and to cases where the public goods are supplied continuously rather than discretely.

Consider a family with $n$ members where the utility of each household member $i$ can be expressed as $U_{i}\left(u_{1}\left(c_{1}, y\right), \ldots, u_{n}\left(c_{n}, y\right)\right)$. where $c_{i}$ is the vector of private consumption goods consumed by $i$ and where $y$ is the vector of household public goods consumed by the family. The assumption of nonmalevolence means that $U_{i}$ is an increasing function of $u_{i}$ and a non-decreasing function of $u_{j}$ for all $j \neq i$. Therefore if an allocation is Pareto optimal (in terms of the $U_{i}$ 's), it must be that this allocation would also be Pareto optimal for an economy of selfish people in which each $i$ has a utility function $u_{i}\left(x_{i}, y\right)$ But this means that any conditions which are necessary conditions for optimality in this selfish family are also necessary conditions for optimality in the actual benevolently related family.

For our example of the husband, wife, and car it is easy to see that if the price of the car is less than $H_{1}+W_{1}$ then they can achieve a Pareto improvement by buying the car and dividing the costs so that the husband gives up less than $H_{1}$ dollars worth of private goods and the wife gives up less than $W_{1}$ dollars worth of private goods. Now consider the case where the price of the car exceeds $H_{1}+W_{1}$. Imagine for the moment that they were selfish with private utilities $u_{i}\left(c_{i}, y\right)$. One can show that for any affordable allocation of resources in which they buy the car, there will be another allocation in which
they do not buy the car such that both of their private utilities will be higher. But since their preferences are benevolent, it follows that for any allocation in which they buy the car there is another allocation which is Pareto superior in terms of their true benevolen preferences where they do not buy the car. If they were to use a decision rule such as "Buy the car if $H_{1}+W_{1}+H_{2}+W_{2}$ exceeds the price" they would act inefficiently whenever the price lies between $H_{1}+W_{1}$ and $H_{1}+W_{1}+H_{2}+W_{2}$

Where the quantity of public goods is a continuous variable and consumers are selfish the fundamental benefit-cost result for efficient supply of public goods in an economy is the Samuelson first-order condition (Samuelson (1954)) which requires that the sum of all individuals' marginal rates of substitutions between the public good and their own private consumption equals the marginal cost of public goods in terms of private goods. Since the Samuelson condition is a necessary condition for Pareto optimality in the selfish family where individual preferences are $u_{i}\left(c_{i}, y\right)$, and since Pareto efficiency in this selfish family is necessary for Pareto efficiency in the corresponding benevolent family, the Samuelson conditions measured from the selfish utility functions must be satisfied in order for their to be efficiency in the benevolent family.

This issue has led to an interesting discussion in the public policy literature about how to value persons' lives-a discussion which has recently been organized and clarified 
by Michael Jones-Lee (1991, 1992). According to Jones-Lee, the traditional prescription for evaluating a public project that saves "statistical lives" is that the evaluation should include not only people's willingness to pay for their own safety, but the sum of amounts people would be willing to pay for improvements in the safety of others. ${ }^{31}$ Jones-Lee points out that Bergstrom (1982) proved that this prescription is "unequivocably inappropriate" in the special case where altruism takes the form of pure concern for other people's utilin the special case where altruism takes the form of pure concern for other people's util-
ity. Bergstrom's 1982 argument is essentially the same as the argument made above for household public goods, but was specialized to the analysis of risks to life.

Bergstrom (1982) and Jones-Lee (1991) pose the problem as follows. Consider a society in which each person has private preferences of the form $u_{i}\left(\pi_{i}, w_{i}\right)=\pi_{i} u_{i}\left(w_{i}\right)$ where $\pi_{i}$ is $i$ 's probability of survival and $w_{i}$ is $i$ 's wealth available for private consumption. Survival probabilities of each individual $i$ are determined as functions $\pi(s)$ where $s$ is public expenditures on safety. In the case where everyone is selfish, the Samuelson condition for Pareto efficiency is that the sum of individual marginal rates of substitution between survival probability and wealth should equal the marginal cost of an extra unit of public expenditures on safety. But suppose that some people in the society care about each others' well-being. Bergstrom and Jones-Lee show that if this interpersonal concern takes the form of pure benevolence, then the same rule that applies for selfish individuals also applies for benevolent individuals. Jones-Lee models the case of "safety-focussed altruism" in which people's only concern with the well-being of others is with their survival probabilities. In this case, he shows that it is appropriate in benefit-cost analysis to add people's willingness to pay for other people's survival probabilities to their willingness to pay for their own. Jones-Lee (1992) suggests an interesting alternative model of interdependent preferences, which he calls paternalistic preferences, in which each person is "benevolent" towards others, but instead of accepting the other person's relative valuation of survival probability and wealth, the paternalistic individual wishes to impose his own relative values on the recipient. Jones-Lee shows that with this kind of paternalistic preferences under reasonable assumptions in a large population the appropriate rule for benefit-cost is to count only individual's own evaluations of risks to their lives.

\section{IV.s. Evolutionary Models of Benevolence with the Family}

In recent years, evolutionary biologists have developed a body of formal theory of the amount of altruism that can be expected to emerge among relatives in sexually-reproducing species. J. B. S. Haldane (1955) remarked that according to evolutionary theory, one should be prepared to rescue a sibling from drowning if the likelihood of saving the sibling's life is at least twice the risk to one's own. To induce one to take the same risk for a first cousin the likelihood of saving the cousin's life must be at least eight times the risk of drowning oneself.

William Hamilton's remarkable papers $(1964 a, b)$ were the first to work out a formal justification for Haldane's calculus of altruism. Hamilton's main result has come to be 31 This prescription is advanced in E.J. Mishan's (1971) classic paper on the evaluation of human life
and safety as well as in papers by L. Needleman (1976), Jones-Lee (1976), and W.K. Viscusi et al (1988). known as "Hamilton's Rule". Hamilton states his rule as follows:

"The social behavior of a species evolves in such a way that in each distinct behaviorevoking situation the individual will seem to value his neighbors' fitness against his own according to the coefficients of relationship appropriate to that situation." (1964b, p 19.)

According to Hamilton's rule, natural selection will favor genes that lead a creature to be willing to exchange its own expected number of offspring for those of a relative so long as $c / b<r$, where $c$ is the cost of the action in terms of ones own expected offspring, $b$ is the gain to the relative and $r$ is the "coefficient of relatedness" between the individual and his relative. For diploid, sexually-reproducing species with random mating, $r$ is $1 / 2$ for offspring and full siblings, $1 / 4$ for grandchildren and half-siblings, 1/8 for great grandchildren and first cousings, and so on.

Richard Dawkins book, The Selfish Gene (1976) popularized Hamilton's theory in a way that many economists have found accessible and stimulating. Dawkins adocates the viewpoint that the replicating agent in evolution is the gene rather than the animal. If a gene carried by one animal is likely to appear in its relatives, then a gene for helping one's relatives, at least when it is cheap to do so, will prosper relative to genes for totally selfish behavior. Robert Trivers book Social Evolution (1985) explores numerous applications of the theory of the evolution of altruism and conflict between relatives. This book is a pleasure to read, with a fascinating mixture of theories and applications of the theories throughout the animal kingdom.

Hamilton's rule is intriguing because because it not only predicts a limited degree of altruism toward relatives, but makes explicit predictions of the degree of altruism as a function of the degree of relationship. Since the environments that shaped our genes are hidden in the distant past, most economists are skeptical about the usefulness of evolutionary hypotheses for explaining human preferences. Still, such fundamental features of family life as mating, child-rearing, and sibling relations are remarkably similar across existing cultures ${ }^{32}$ and are likely not to have changed drastically over the millennia. This suggests that evolutionary theory can be expected to enrich the economics of the family. ${ }^{33}$

Trivers (1985) applies the Hamilton theory to parent-offspring conflict and to sibling rivalry and sibling conflict. According to Hamilton's theory, in a sexually reproducing diploid species, full siblings (who on average have half of the their genes in common) will tend to value each others survival probability half as much as they value their own. Parent on the other hand, will value the survival probabilities of each offspring equally. Trivers illustrates these theoretical problems with field observations of feeding conflicts between mother and offspring and among siblings in several species of birds and mammals.

Hamilton proves his propositions only for environments where costs and benefits are purely additive. That is, each individual's survival probability can be expressed as a sum of

32 Anthropology book

33 This view seems to be shared by Gary Becker (1976) and Jack Hirshleifer (1978). Hirshleifer's paper contains an engaging manifesto on behalf of an evolutionary theory of preference formation. 
"gifts" given to or received from relatives. Bergstrom (1992) extends the Hamilton model as applied to altruism between siblings so as to allow more general interactions in which benefits and costs from helping others may be non-linear and non-separably interactive.

Bergstrom and Stark (1993) offer a series of models in which altruism between siblings and neighbors persists under evolutionary pressures. In these models, inheritance may be either genetic or "cultural."

\section{IV.6. Conscious Choice of Altruism}

\section{When is More Love not a Good Thing?}

In evolutionary models, the degree of altruism is selected endogenously by forces of natural selection. Bernheim and Stark (1988) consider some issues that arise if people are to able to make conscious choices about how much to love others. Choices of this kind are especially pertinent to courtship and marriage. The metaphor "falling in love" suggests a certain lack of control of the process, but even here, one has some choice in choosing which precipices to approach.

Bernheim and Stark find interesting examples in which an increase in love of one individual may be bad for both the lover and the beloved. They parameterize love as a particular kind of interdependence of utility functions and show that altering the amount of love in a relationship can have surprising effects. For example, suppose that one member of a couple is naturally unhapy. If his partner were to increase her love for him, she would unhappy beloved would see become even more miserable when he observes her reduced happiness.

Bernheim and Stark find further paradoxes in the application of cooperative game theory to people who love each other. Consider two players in a nonzero-sum game. Suppose that an increase in one person's love is defined as making that person's payoff a convex combination of his own and his partner's payoff with an increased weight on the partner's payoff. In the Nash equilibrium for the resulting game, an increase in love may turn out to decrease rather than increase the payoffs of one or both partners. Bernheim and Stark also show that increased love may make both parties worse off in multi-stage munishment strategies as credible threats and hence result in a Pareto inferior equilibrium.

\section{Maximizers and Imitators}

Donald Cox and Oded Stark (1992) suggest it may be that selfish people would choose to be kind to their aged parents because this behavior may be "imprinted" on their own children, who will in turn treat their parents as they saw their parents treat their grandparents. Parents would then find it in their self-interest to treat their parents as they would like to be treated themselves when they are old.
As Bergstrom and Stark (1993) remark, it would be incongruous to assume that each generation rationally select's its behavior towards its parents while believing that the behavior of its children will is not a maximizing choice, but it predetermined by imprinting. Bergstrom and Stark suggest a model in which some people turn out to be maximizers and some to be imitators. Parents who happens to be a maximizer does not know for certain whether their children will blindly imitate their parents behavior or will choose their behavior to maximize their own self-interest.

For example, consider a model in which an adult couple who are maximizers seek to maximize an intertemporal expected utility function $U(x, y)$, where $x$ is their action toward their parents and where $y$ is the action of their children toward them when they are old. Suppose that the children will turn out to be imitators with probability $\pi$ and maximizers with probability $1-\pi$. Suppose further that the environment is stationary across generations so that maximizers in any generation have the same utility functions and face the same probabilities that their children will be maximizers.

If maximizing parents believe that maximizing children will take action $y$, then they will choose an action $\bar{x}(y)$ that maximizes her expected utility,

$$
\pi U(x, x)+(1-\pi) U(x, y)
$$

Since the environment is assumed to be stationary, if the children happen to be maxmizers, they will face the same maximization problem as their parents. Therefore the action $y$ taken by maximizing children will be the same as the action $\bar{x}(y)$ of maximizing parents. In equilibrium, maximizers will choose $\mathrm{x}$ to maximize $\pi U(x, x)+(1-\pi) U(x, \bar{x})$ and in equilibrium it will be true that this maximizing $x$ is equal to $\bar{x}$. Imitators, being imitators, will choose the same $\bar{x}$.

Where the utility function $U$ is differentiable, the first-order necessary condition for maximizers is $U_{1}(\bar{x}, \bar{x})+\pi U_{2}(\bar{x}, \dot{\bar{x}})=0$, where $U_{\mathrm{i}}(x, y)$ is the partial derivative of $U$ with respect to its $i$ th argument. Therefore in equilibrium the marginal cost $-U_{1}(\bar{x}, \bar{x})$ of respect to its $i$ th argument. Therefore in equilibrium the marginal cost $-U_{1}(\bar{x}, \bar{x})$ of
kindnesses to parents is equal to $\pi$ times the marginal benefits of kindness received from their children. Where $U$ is a concave function, it can be demonstrated that the equilibrium utility of each generation is an increasing function of $\pi$ so long as $\pi<1$. Thus we have the paradoxical result that so long as the family produces an occasional maximizer, the more likely children are to imitate their parents rather than to rationally maximize, the better off all family members will be. 


\section{References}

Archibald, G.C. and Donaldson, David (1976) "Non-paternalism and the Basic Theorems of Welfare Economics," Canadian Journal of Economics, 9, 492-507.

Barro, R. (1974) "Are Government Bonds Net Wealth?," Journal of Political Economy, 82, 1095-1117.

Becker, Gary (1965) "A Theory of the Allocation of Time," Economic Journal, 75, 493-517. Becker, G. (1974) "A Theory of Social Interactions," Journal of Political Economy, 82, 1063-1094.

Becker, G. (1976) "Altruism, Egoism, and Fitness: Economics and Sociobiology," Journal of Economic Literature, 14,

Becker, Gary (1981) A Treatise on the Family. Cambridge, Mass.: Harvard University Press.

Bergson, Abram (1938) "A Reformulation of Certain Aspects of Welfare Economics," Quarterly Journal of Economics, 52, 310-334.

Bergstrom, Theodore (1971a) "A 'Scandinavian Consensus' Solution for Efficient Allocation With Non-Malevolent Preferences," Journal of Economic Theory, 2, 383-398.

Bergstrom, Theodore (1971b) "Interrelated Consumer Preference and Voluntary Exchange," in Papers in Quantitative Economics, ed. Zarley, A.. Lawrence, Kansas: Kansas University Press, 79-94.

Bergstrom Theodore, and Cornes, Richard (1981) "Gorman and Musgrave are Dual-An Antipodean Theorem on Public Goods," Economic Letters, , 371-378.

Bergstrom Theodore, and Cornes, Richard (1983) "Independence of Allocative Efficiency from Distribution in the Theory of Public Goods," Econometrica, 51, 1753-1765.

Bergstrom Theodore, and Varian, Hal (1985) "When Do Market Games Have Transferable Utility," Journal of Economic Theory, 35, 222-233.

Bergstrom, Theodore, Larry Blume, and Hal Varian (1986) "On the Private Supply of Public Goods," Journal of Public Economics, 29, 25-49.

Bergstrom, Theodore (1988) "Systems of Benevolent Utility Interdependence," University of Michigan working paper.

Bergstrom, T. and Lam, D. (1989a) "The Effects of Cohort Size on Marriage Markets in Twentieth Century Sweden," in The Family, the Market, and the State in Industrialized Countries, ed. . : Oxford University Press.

Bergstrom, T. and Lam, D. (1989b) "The Two-sex Problem and the Marriage Squeeze in an equilibrium Model of Marriage Markets," University of Michigan Working Paper.

Bergstrom, Theodore (1989) "A Fresh Look at the Rotten Kid Theorem," Journal of Political Economy, 87, 1138-1159.

Bergstrom, Theodore (1989) "Love and Spaghetti, The Opportunity Cost of Virtue," Journal of Economic Perspectives, 3, 165-173.
Bergstrom, Theodore (1993) "Courtship as a Waiting Game," Journal of Political Economy, 101, 185-202.

Bergstrom, Theodore and Stark, Oded (1993) "How Altruism Can Prevail in an Evolutionary Environment," American Economic Review (Papers and Proceedings), 83, 149-155.

Bernheim, B. Douglas and Stark, Oded (1988) "Altruism within the Family Reconsidered: Do Nice Guys Finish Last?," American Economic Review, , 1034-1045.

Bernheim, B. Douglas and Bagwell, Kyle (1988) "Is Everything Neutral?," Journal of Political Economy, 96, 308-338.

Binmore, Kenneth George (1985) "Bargaining and Coalitions," in Game-Theoretic Models of Bargaining, ed. Alvin Roth. Cambridge: Cambridge University Press, 259-304.

Binmore, Kenneth George (1987) "Perfect Equilibrium in Bargaining Models," in The Economics of Bargaining, ed. Ken Binmore and Partha Dasgupta. Oxford: Blackwell.

Binmore, Kenneth, Shaked, Avner, and Sutton John (1989) "An Outside Option Experiment," Quarterly Journal of Economics, , 753-770.

Blackorby Charles, Primont, Daniel and Russell, R. Robert (1978) Duality, Separability and Functional Structure: Theory and Economic Applications. New York: North Holland.

Browning, M., Children and Household Economic Behavior (1992) “," Journal of Economic Literature, 30, 1434-1475.

Browning, Martin, Bourguignon, François, Chiappori, Pierre-André, and Lechene, Valérie (1992) "A Structural Empirical Modeo of Within Household Allocation," McMaster University working paper.

Bruce, Neil and Waldman, Michael (1990) "The Rotten-kid Theorem Meets the Samaritan's Dilemma," Quarterly Journal of Economics, 105, 155-65.

Buchanan, James (1975) "The Samaritan's Dilemma," in Altruism, Morality, and Economic Theory, ed. Edmund Phelps. New York: Russell Sage Foundation, 71-85.

Campbell, Donald and Truchon, Michael (1988) "Boundary Optima and the Theory of Public Goods Supply," Journal of Public Economics, 35,

Coleman, James (1990) Foundations of Social Theory. Cambridge, MA: Harvard University Press.

Chipman, John (1974) "Homothetic Preferences and Aggregation," Journal of Economic Theory, 8, 26-28.

Chiappori, Pierre-André (1988) "Rational Household Labor Supply," Econometrica, 56, 63-90.

Chiappori, Pierre-André (1992) "Collective Labor Supply and Welfare," Journal of Political Economy, 100, 437-467.

Danzig, George (1951) "Application of the Simplex Method to the Transportation Problem," in Activity Analysis of Production and Allocation, ed. Tjalling C. Koopmans. New York: Wiley 
Das Gupta, Prithwis (1973) "Growth of the U.S. Population, 1940-1971, in the Light of an Interactive Two-Sex Model," Demography, 10, 543-565.

Dawkins, R. (1976) The Selfish Gene. New York: Oxford University Press.

Deaton, Angus and Muellbauer, John (1980) Economics and Consumer Behavior. Cambridge: Cambridge University Press.

Demange, Gabriella and Gale, David (1985) "The Strategy Structure of Two-Sided Matching Models," Econometrica, 53, 873-88.

Diamond, Peter (1965) "National Debt in a Neoclassical Growth Model," The American Economic Review, 55, 1126-1149.

Diamond, Peter (1965) "The Evaluation of Infinite Utility Streams," Econometrica, 33, 170-177.

Diewert, Erwin (1977) "Generalized Slutsky Conditions, for Aggregate Consumer Demand Functions," Journal of Economic Theory, 15, 333-336.

Eisenberg, E. (1961) "Aggregation of Utilities," Management Science, 7, 337-350.

Gale, David (1960) The Theory of Linear Economic Models. New York: McGraw-Hill.

Gale, David and Shapley, Lloyd (1962) "College Admissions and the Stability of Marriage," American Mathematical Monthly, 69, 9-15.

Gorman, W.M. (1953) "Community Preference Fields," Econometrica, 21, 63-80.

Haddad, Lawrence and Hoddinott, John (1991) "Household Expenditures, Child Anthropomorphic Status and the Intrahousehold Division of Income: Evidence from the Cote d' Ivoire," Princeton University Research Program in Development Studies, Discussion Paper 155.

Haldane, J. B. S. (1955) “" New Biology, 18, 34-51

Hamilton, W. D. (1964a) "The Genetical Evolution of Social Behavior. I," Journal of Theoretical Biology, 7, 1-16.

Hamilton, W. D. (1964b) "The Genetical Evolution of Social Behavior. II.," Journal of Theoretical Biology, 7, 17-52.

Hicks, John R. (1956) A Revision of Demand Theory. Oxford: Oxford Clarendon.

Hirshleifer, J. (1977) "Economics from a Biological Viewpoint," Journal of Law and Eco. nomics, , 1-52.

Hirshleifer, J. (1978) "Natural Economy Versus Political Economy," Journal of Social and Biological Structures, 1, 319-337.

Hori, H. and Kanayo, S. (1989) "Utility Functionals with Nonpaternalistic Intergenerational Altruism," Journal of Economic Theory, 49, 241-255.

Hori, H. (1990) "Utility Functionals with Nonpaternalistic Intergenerational Altruism: The Case Where Altruism Extends to Many Generations," Working Paper, ,
Johnson, David S. (1990) "Team Behavior in the Family: An Analysis of the Rotten Kid Theorem," Bureau of Labor Statistics working paper.

Jones-Lee, Michael (1991) "Altruism and the Value of Other People's Safety," Journal of Risk and Uncertainty, 4, 213-219.

Jones-Lee, Michael (1992) "Paternalistic Altruism and the Value of Statistical Life," The Economic Journal, 102, 80-90.

Kaneko, Manoru (1982) "The Central Assignment Game and the Assignment Markets," Journal of Mathematical Economics, 10, 205-232.

Kemeny, J. Snell, J., and Knapp, A. (1966) Denumerable Markov Chains. Princeton, N. J.: Van Nostrand

Keyfitz, Nathan (1971) "The Mathematics of Sex and Marriage," in Proceedings of the Sixth Berkeley Symposium on Mathematical Statistics and Probability, ed. . Berkeley: University of California Press.

Kimball, M. (1987) "Making Sense of Two-Sided Altruism," Journal of Monetary Economics, 20, 301-326.

Knuth, Donald (1976) Marriages Stables. Montreal: Les Presses de l'Université de Montreal.

Koopmans, Tjalling, and Beckman, Martin (1957) "Assignment Problems and the Location of Economic Activities," Econometrica, 25, 53-76.

Koopmans, Tjalling (1960) "Stationary Ordinal Utility and Impatience," Econometrica, 28, 287-309.

Laitner, John (1979a) "Household Bequests, Perfect Expectations, and the National Distribution of Wealth," Econometrica, 47, 1175-1194.

Laitner, John (1979b) "Bequests, Golden-Age Capital Accumulation and Government Debt," Economica, 46, 403-414.

Laitner, John (1988) "Bequests, Gifts, and Social Security," Review of Economic Studies, 55, 275-299.

Laitner, John (1990) "Intergenerational Preference Differences and Optimal National Saving," Journal of Economic Theory, 22, 56-66.

Laitner, John (1991) "Modeling Marital Connections among Family Lines," Journal of Political Economy, 99, 1123-1141.

Lam, David (1988) " Marriage markets and assortative mating with household public goods," Journal of Human Resources, 23, 462-487.

Lindbeck, Assar and Weibull, Jörgen (1988) "Altruism and Efficiency, the Economics of Fait Accompli," Journal of Political Economy, 96, 1165-82.

Lundberg, Shelly and Pollak, Robert (1991) "Separate Spheres Bargaining and the Marriage Market," University of Washington working paper. 
Manser, Marilyn and Brown, Murray (1980) "Marriage and Household Decision Theory-A Bargaining Analysis," International Economic Review, 21, 21-34.

Marshack, Jacob and Radner, Roy (1972) Economic Theory of Teams. New Haven: Yale University Press.

Matzkin, Rosa and Streufert, Peter (1991) "On Interdependent Utility," University of Wisconsin working paper.

McElroy, Marjorie and Horney, Mary (1981) "Nash-Bargained Decisions: Toward a Gen eralization of the Theory of Demand," International Economic Review, 22, 333-349.

McElroy, Marjorie (1990) "The Empirical Content of Nash-Bargained Household Behavior," Journal of Human Resources, 25, 559-583.

McFarland, D. (1972) "Comparison of Alternative Marriage Models," in Population Dynamics, ed. T.E. Greville. New York: Academic Press, 89-106.

McKenzie, Lionel (1960) "Matrices with Dominant Diagonals and Economic Theory," in Mathematical Methods in the Social Sciences, ed. Arrow, Kenneth, Karlin Samuel, and Suppes, Patrick. Stanford, CA: Stanford University Press.

Mishan, E.J. (1971) "Evaluation of Life and Limb: A Theoretical Approach," Journal of Political Economy, 79, 687-705.

Moldevanu, Benny (1990) "Stable Bargained Equilibria for Assignment Games Without Side Payments," International Journal of Game Theory, 19, 171-190.

Muth, Richard (1966) "Household Production and Consumer Demand Functions," Econo. metrica, 34, 699-708.

Nash, John (1950) "The Bargaining Problem," Econometrica, 18, 155-62.

Needleman, L. (1976) "Valuing Other People's Lives," Manchester School, 44, 309-342.

Parks, Robert (1991) "Pareto Irrelevant Externalities," Journal of Economic Theory, 54, 165-179.

Pearce, David (1983) "Nonpaternalistic Sympathy and the Inefficiency of Consistent Intertemporal Plans," Cowles Foundation Working paper, Yale University.

Phelps, Edwin and Pollak, Robert (1968) "On Second-Best National Saving and Game-Equilibrium Growth," Review of Economic Studies, 35, 185-200.

Pollak, R. (1968) "Consistent Planning," Review of Economic Studies, 35, 201-208.

Pollak, Robert and Wachter, Michael (1975) "The Relevance of the Household Production Function and Its Implications for the Allocation of Time," Journal of Political Economy, 68, 349-359.

Pollak, Robert (1986) "A Reformulation of the Two-Sex Problem," Demography, 23, 247-259.

Rader, Trout (1964) "Edgeworth Exchange and General Economic Equilibrium," Yale Economic Essays, 4, 133-180.
Rochford, Sharon (1984) "Symmetrically Pairwise-Bargained Allocations in an Assignment Market," Journal of Economic Theory, 34, 262-281.

Roth, David (1992) "A Theory of Partnership Dynamics, Learning, Specific Investment, and Dissolution," University of Michigan working paper.

Roth, Alvin and Sotomayor, Marilda (1990) Two-sided Matching. Cambridge: Cambridge University Press.

Samuelson, Paul (1947) Foundations of Economic Analysis. Cambridge: Harvard University Press.

Samuelson, Paul (1950) "Evaluation of Real National Income," Oxford Economic Papers, II, 1-20.

Samuelson, Paul (1954) "The Pure theory of Public Expenditures," Review of Economics and Statistics, 36, 387-389.

Samuelson, Paul (1956) "Social Indifference Curves," Quarterly Journal of Economics, 70 1-22.

Samuelson, Paul (1958) "An Exact Consumption-Loan Model of Interest with or without the Social Contrivance of Money," Journal of Political Economy, 66, 467-482.

Samuelson, Paul (1961) "A New Theorem on Nonsubstitution," in Money, Growth and Methodology, Published in honor of Johan Akerman, ed. . Lund, Sweden: Lund Social Science Studies, 407-423.

Schultz, T. Paul (1990) "Testing the Neoclassical Model of Family Labor Supply and Fertility," Journal of Human Resources, 25, 599-634.

Shafer, Wayne (1977) "Revealed Preference and Aggregation," Econometrica, 45, 1173-1182.

Shaked, Avner and Sutton, John (1984) "Involuntary Unemployment as a Perfect Equilibrium in a Bargaining Model," Econometrica, 52, 1351-64.

Shapiro, Perry (1977) "Social Utility Functions," Journal of Economic Theory, 16, 475-480.

Rubinstein, Ariel (1982) "Perfect Equilibrium in a Bargaining Model," Econometrica, 50, 97-109.

Rubinstein, Ariel and Wolinsky, Asher (1985) "Equilibrium in a Market with Sequential Bargaining," Econometrica, 53, 1133-1150.

Shapley, Lloyd, and Shubik, Martin (1972) "The Assignment Game I: The Core," International Journal of Game Theory, 1, 111-130.

Strotz, R. (1955) "Myopia and Inconsistency in Dynamic Utility Maximization," Review of Economic Studies, 23, 165-180.

Sutton, John (1986) "Noncooperative Bargaining Theory: An Introduction," Review of Economic Studies, 53, .

Thomas, Duncan (1990) "Intra-household Resource Allocation: An Inferential Approach," Journal of Human Resources, 25, 635-696. 
Trivers, R. (1985) Social Evolution. Menlo Park, Ca.: Benjamin/Cummings.

Varian, Hal (1983) "Nonparametric Tests of Consumer Behavior," Review of Economic Studies, 50, 99-110.

Varian, Hal (1984) "Social Indifference Curves and Aggregate Demand," Quarterly Journal of Economics, 99, 403-414.

Viscusi, W.K., Magat, W.A., and Forest, A. (1988) "Altruistic and Private Valuations of Risk Reduction," Journal of Policy Analysis and Mangement, 7, 227-245.

Weiss, Yoram and Willis, Robert (1985) "Children as Collective Goods in Divorce Settlements," Journal of Labor Economics, 3, 268-292.

Weiss, Yoram and Willis, Robert (1991) "Transfers among Divorced Couples: Evidence and Interpretation," University of Chicago/NORC working paper.

Winter, Sidney (1969) "A Simple Remark on the Second Optimality Theorem of Welfare Economics," Journal of Economic Theory, 1, 99-103. 